S. Jürgens, P. Oßwald, M. Selinsek, P. Piermartini, J. Schwab, P. Pfeifer, U. Bauder, S. Ruoff, B. Rauch, M. Köhler, Assessment of combustion properties of non-hydroprocessed Fischer-Tropsch fuels for aviation, Fuel Processing Technology 193 (2019) 232-243.

The original publication is available at www.elsevier.com

https://doi.org/10.1016/j.fuproc.2019.05.015

(C) <2019>. This manuscript version is made available under the CC-BY-NC-ND 4.0 license http://creativecommons.org/licenses/by-nc-nd/4.0/ 


\title{
Assessment of combustion properties of non-hydroprocessed Fischer-Tropsch fuels for aviation
}

\author{
Sophie Jürgens ${ }^{1}$, Patrick Oßwald ${ }^{1}$, Manuel Selinsek ${ }^{2}$, Paolo Piermartini ${ }^{2}$, Johannes Schwab ${ }^{3}$, Peter, \\ Pfeifer $^{3}$, Uwe Bauder ${ }^{1}$, Stephan Ruoff ${ }^{1}$, Bastian Rauch ${ }^{1}$ and Markus Köhler ${ }^{1}$ \\ ${ }^{1}$ Institute of Combustion Technology, German Aerospace Center (DLR), Pfaffenwaldring 38- 40, D- \\ 70569 Stuttgart, Germany \\ ${ }^{2}$ INERATEC GmbH, Siemensallee 84, D-76187 Karlsruhe, Germany \\ ${ }^{3}$ Institute for Micro Process Engineering, Karlsruhe Institute of Technology (KIT), 76131 Karlsruhe, \\ Germany
}

\begin{abstract}
A demonstrative Fischer-Tropsch fuel without any cost intensive post-processing treatment has been investigated for its application potential as a synthetic blending component with conventional petroleum-derived aviation fuels. As a first step, the focus of the analysis was purely on combustion related properties. The Fischer-Tropsch fuel was obtained via a specific Power-to-Liquid FischerTropsch process, developed by Ineratec. Whereas the already approved Fischer-Tropsch-SPK process (ASTM D7566 Annex A1) utilizes hydrotreatment and is applied in large-scale plants, the herein presented plant features a unique and compact container-scale set-up, with no further downstream hydrotreatment, which allows for a significant reduction of production time and costs. Main objective of this paper is to provide the fuel producer with fast feedback to find the minimum complexity of fuel processing technology to achieve a synthetic blending component for aviation fuels directly from a container plant. As a first step in the ongoing process, the combustion properties of the non-hydroprocessed Fischer-Tropsch fuels are assessed regarding their suitability for aviation purposes.
\end{abstract}

Fuel characterization was carried out regarding the physiochemical properties of the fuels and their chemical composition to monitor selected "fit-for-purpose" properties for aviation with regard to combustion properties. Additional combustion experiments were conducted in a high-temperature flow-reactor with coupled molecular beam mass spectrometer (MBMS) for two stoichiometries to map lean and rich combustion $(\Phi=0.8$ and 1.2 ), allowing quantitative access to the chemical reaction species formed within the combustion. The general combustion chemistry and reaction temperature regime was found similar to Jet $A-1$ and pure $n$-alkane decane. This indicates the dominant species for the observed combustion process are aliphatic hydrocarbons. The detailed evaluation of relevant intermediates allows for an observation on typical soot precursors (e.g. benzene, naphthalene) in the combustion process and enables the estimation on the pollutant reduction potential of the Fischer-Tropsch fuel when used as blending component to Jet A-1. 
Blending analysis has been performed utilizing the data from the CRC world fuel survey to evaluate the range of blending ratios of the Fischer-Tropsch fuel with conventional jet fuels determined by identified limiting factors. The presented evaluations demonstrate the potential of the FischerTropsch fuel as a blending component with conventional jet fuels considering the combustion behavior only.

Keywords: Fischer-Tropsch fuels; synthetic paraffinic kerosene; Fisher-Tropsch plant; alternative fuels; aviation fuels; Molecular Beam Mass Spectrometer (MBMS) 


\section{Introduction}

The development and applicability of renewable fuels represent a substantial research field in the aviation sector with respect to reduction of $\mathrm{CO}_{2}$, soot, and toxic precursors as well as overcoming the dependency from fossil fuels. Recent studies under real-life conditions with renewable fuels in ground and in-flight measurement campaigns emphasize the positive impact of alternative fuels as blending component on emission reduction ${ }^{1-3}$.

Sustainable aviation fuels (SAF) have already been introduced into commercial aviation in 2008 when the first flight was conducted by a Virgin Atlantic B747 using a blend of Jet A-1 and sustainable aviation fuel ${ }^{4}$. Ever since, numerous alternative fuels have been demonstrated to be possible to fly on and in 2011 over 100.000 flights worldwide with SAF blends have been performed on a commercial level ${ }^{5}$. In order to meet the IATA (International Air Transport Association) carbon reduction target of a cut of $50 \%$ in aviation $\mathrm{CO}_{2}$ emissions by 2050 compared to $2005^{4}$, significant efforts concerning alternative fuel synthesis and utilization have to be undertaken. Fischer-Tropsch-synthesis (FTS) presents therein a valid alternative route to produce paraffinic hydrocarbons. In this process, hydrogen and a carbon source are converted into syngas $\left(\mathrm{H}_{2}\right.$ and $\left.\mathrm{CO}\right)$ in a first reaction step and are subsequently transformed ${ }^{6}$. The obtained synthetic hydrocarbons can be used as feedstock for the chemical industry or for the production of synthetic fuels such as diesel or kerosene. The synthesis itself is a heterogeneously catalyzed conversion of the beforehand produced syngas in primarily liquid hydrocarbons and solid waxes. The catalyzed process displays furthermore the benefit that the fuels are practically free of any foreign contaminants such as sulfur $^{7-8}$. By altering synthesis parameters such as pressure, reaction times and temperatures or the utilized catalyst as well as the condensation temperatures, the distribution of chain length and of species (isomers, linear chains and olefin content) of the respective Fischer-Tropsch fuels can be varied.

Starting already in 1999, Sasol's Semi Synthetic Jet Fuel (SSJF) made from coal and natural gas by coal to liquid (CTL) synthesis has been applied as a $50 \%$ blend with conventional jet fuel at the Johannesburg Airport ${ }^{9-10}$. This Fischer-Tropsch fuel blend was the first (locally and) commercially established one in the aviation sector, followed by the fully synthetic jet fuel (FSJF) also produced by Sasol, which gained first-time approval for international use in commercial aviation in $2008^{11}$. FSJF fuels contain a relatively high amount of aromatic hydrocarbons at around $20-25 \%$ in comparison to more common FT fuels, which are normally comprised of $\mathrm{n}$ - and iso-alkanes and contain little to no aromatics. The minimum aromatic content of alternative jet fuels is currently set at $8 \%$ by the ASTM norm D7566 ${ }^{12}$ 
for aviation turbine fuel containing synthesized hydrocarbons. Historically, this regulation addresses the concern that engine leakage might appear, when aromatic content of the fuel is too low. Several studies and literature reviews such as by Blakey, Moses, Baltrus et al. have addressed this topic by evaluating the swelling potential of O-rings due to fuel additives ${ }^{13-19}$. It was demonstrated that compounds incorporating aromatic functionalities display one of the best sealant volume swells. This has been contributed to an interaction between the complementary functionalities on these compounds and the macromolecular sealant materials such as polysulfide or nitrile rubber ${ }^{13}$. From a technical point of view engine leakage is contributed to shrinking of ageing seals with respect to the low aromatic content. Regarding Sasols' FSFJ fuel, the relative high amount of aromatics made it in regard to component compatibility more suitable as a jet fuel.

However, the ecoDemonstrator program by Boeing demonstrated the feasibility on flying solely on biofuels on a 777 Freighter ${ }^{20-22}$, with one of the tested fuels being $100 \%$ aromatic free hydroprocessed esters and fatty acids (HEFA) biofuels. The ecoDemonstrator program is currently in its fifth iteration with flight testing having started in March 2018 to demonstrate the drop-in fuel properties of $100 \%$ aromatic free HEFA biofuels ${ }^{23}$. These finding are also supported by various ground measurement studies with aromatic free (alternative) jet fuels as conducted in emission measurements ${ }^{24-28}$. Schripp et al. for example could demonstrate the engine compatibility of $100 \%$ aromatic free ATJ SPK (alcohol-to-jet synthetic paraffinic kerosene) on real airplane engines ${ }^{29}$. Fischer-Tropsch fuels in particular have been shown to display multiple benefits being tested solely or as blends with conventional fuels. Soot reduction, as well as decreased ground-level particulate emissions and decreased sulfurbased emissions for example were demonstrated for the use of pure Fischer-Tropsch fuels and blends with JP-8 or Jet A-1 in comparison to conventional jet fuels ${ }^{30}$. Subsequently, decreased contrail formation was also observed, as reduced soot emissions decrease the fuel's potential to act as cloud condensation nuclei $(\mathrm{CCN})^{31-32}$. A number of ground-based studies focused on the emissions impacts associated with alternative fuels. ${ }^{33-36}$ Significantly reduced particle emission for Fischer-Tropsch jet fuel blends on engine exhaust composition could be demonstrated by Schripp et al. during the 2015 ECLIF (Emission and Climate Impact of Alternative Fuels) campaign using an Airbus $A 320^{3}$ with special impact being set on a varying fuel aromatic content on engine particle emissions.

Big scale industrial Fischer-Tropsch plants are well established and have been set up by companies like Sasol and Shell ${ }^{10}$. Commercial scale slurry phase Fischer-Tropsch (FT) reactors or conventional tubular fixed bed reactor (TFBR) are applied for the conversion of syngas to long chain hydrocarbons. Product olefins undergo secondary reactions and 
thereby significantly modify the species and chain length distribution. This generally leads to chain length dependencies of certain olefin reaction possibilities, which are again suited to serve as a characteristic feature for the kind of olefin conversion. These plants however have high demands on capacities and always apply a downstream hydrotreatment. Remote and/or smaller airports typically have to be delivered with aviation fuels via airplanes or lorries, making their supply with fuels cost and time demanding, as well as increasing the carbon footprint significantly. To minimize the ecologic and economic factor, as well as to achieve a fuel independency for those airports, on-site Fischer-Tropsch plants could present a sophisticated approach. Furthermore, surplus electricity from wind- or hydropower plants at low consumption times can be selectively used by the conveniently set up container plant solution to enable local power-to-liquid synthesis in order to obtain Fischer-Tropsch fuels. In this process, hydrogen and a carbon source are converted into syngas $\left(\mathrm{H}_{2}\right.$ and $\left.\mathrm{CO}\right)$ in a first reaction step and subsequently transformed into fuel ${ }^{6}$. Ideally, power supply to produce $\mathrm{H}_{2}$ via water or steam electrolysis is acquired from renewable energy sources. In the context of a decentralized Power-to-Liquid approach, syngas is obtained either by reverse water-gasshift reaction of $\mathrm{CO}_{2}$ and $\mathrm{H}_{2}$ or by high temperature co-electrolysis. $\mathrm{CO}_{2}$ can also be produced directly via "direct air capture" (DAC) which has been demonstrated for various prototypes ${ }^{37-}$ 38. Therefore Fischer-Tropsch-synthesis has the potential of utilizing surplus energy more efficiently, while also being almost $\mathrm{CO}_{2}$ neutral (closed $\mathrm{CO}_{2}$ cycle) within the process at the same time. The herein regarded units of Ineratec consist of synthesis gas production from $\mathrm{CO}_{2}$ and $\mathrm{H}_{2} \mathrm{O}$ via RWGS, Fischer-Tropsch synthesis for the production of long chain hydrocarbons ${ }^{8}$ and can be connected to direct air capture unit for $\mathrm{CO}_{2}$ production and electrolysis.

By altering synthesis parameters such as pressure, reaction times and temperatures or the utilized catalyst, the product distribution of the respective Fischer-Tropsch fuels can be varied. Furthermore, a load flexible production of fuels is possible, since the initiation time of the reactor is significantly shorter for a container scale-up in comparison to big scale industrial Fischer-Tropsch plants. This allows for a distinguished utilization of excess circuit and load cycles in the minute range. The container-scale plants for Fischer-Tropsch fuels as developed by Ineratec would thereby minimize the amount of used conventional jet fuel, making them ecologically end economically significant at the same time. However, an open question is how much fuel downstream processing is required so that the FT-fuel can be used as a blend component for aviation fuels and what the maximum blending ratio would be. 
The German government has set the goal to accomplish a reduction of greenhouse gas emissions by $80-95 \%$ in 2050 in comparison to $1990^{39}$. In this context, the nationally funded Kopernikus projects thrive to develop a decarbonisation of energy systems and storage of renewable energy sources. The transport sector plays therein an important role by contributing around $20 \%$ of the total $\mathrm{CO}_{2}$ emissions in Germany ${ }^{40}$. The use of renewable bio fuels is a valid solution, but limited by soil availability and competing food production. Therefore, so called "e-fuels", produced by renewable hydrogen and carbon sources, were brought to attention. As a consequence, one focus of the Kopernikus project Power-to-X (P2X) is the production of kerosene from power in decentralized autarkical and modular units. While a fully integrated unit is currently being built in cooperation of KIT, Ineratec, Climeworks and Sunfire as part of the project, a study was initiated to evaluate the possibilities of non-hydroprocessed FT fuels as blending components for conventional jet fuels. Within this frame, the decentralized container scale Fischer-Tropsch plant represents a unique approach in the Kopernikus project. The presented work investigates the impact on physical and chemical properties and chemical combustion behavior, the potential influence on pollutant formation and addresses the problem of fuel supply for remote areas.

\section{Compact plant concept}

\subsection{Compact Power-to-Liquid technology}

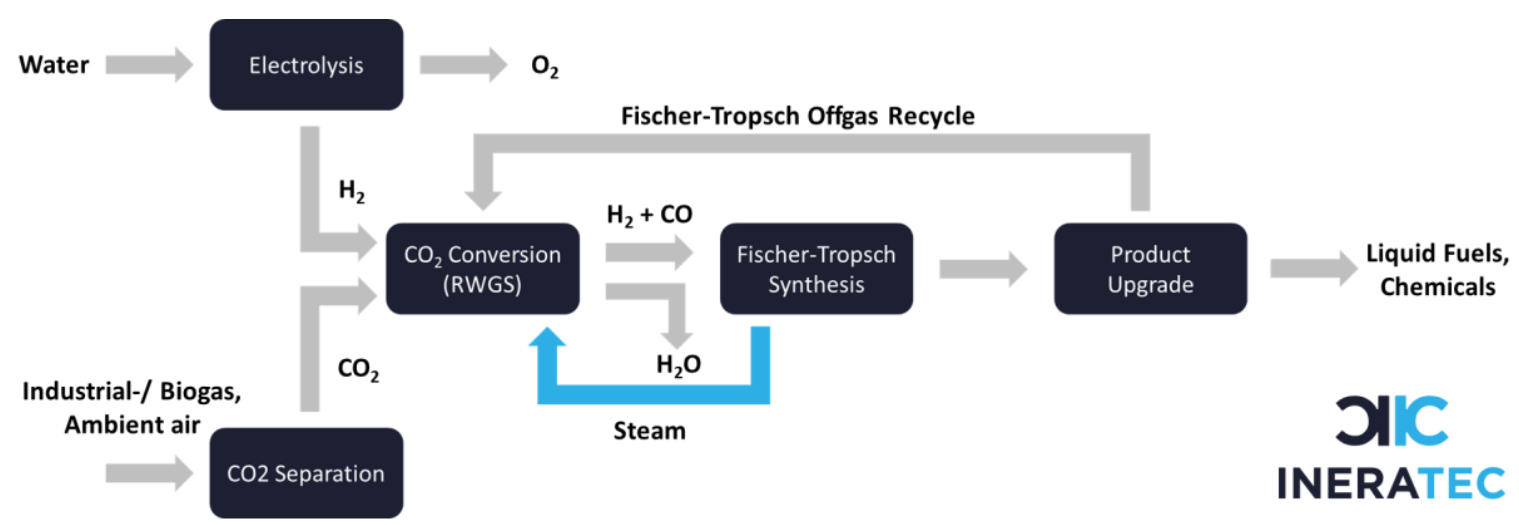

Figure 1: INERATEC's compact Power-to-Liquid plant concept, converting $\mathrm{H}_{2}$ and $\mathrm{CO}_{2}$ into liquid fuels and chemicals.

The aim of the compact plants is the conversion of greenhouse gases to synthetic fuels and valuable chemicals in a decentralized scale as an energy storage solution. Power-to-X processes utilize renewable power, e.g., wind, solar or hydro power, to produce the feed stock for a chemical synthesis. In general, water electrolysis is applied to produce hydrogen, since the technology is broadly available. Whereas $\mathrm{CO}_{2}$ can either be supplied by $\mathrm{CO}_{2}$ emitting processes, e.g., a biogas plant, or by direct air capture. For the production of liquid 
fuels via Fischer-Tropsch synthesis (FTS), $\mathrm{CO}_{2}$ needs to be converted to $\mathrm{CO}$. In the concept presented here, this is accomplished by reverse-water-gas shift (RWGS) reaction as described in Equation 1. The goal is to form a $\mathrm{H}_{2} / \mathrm{CO}$ ratio of 2, which can be considered optimal for FTS. Therefore, temperatures well above $650{ }^{\circ} \mathrm{C}$ are needed to shift the equilibrium towards $\mathrm{CO}$, since its formation is endothermic ${ }^{41}$.

$$
\mathrm{CO}_{2}+\mathrm{H}_{2} \leftrightarrow \mathrm{CO}+\mathrm{H}_{2} \mathrm{O} \quad \Delta_{\mathrm{R}} \mathrm{H}^{0}=41 \mathrm{~kJ} / \mathrm{mol}
$$

The produced syngas, a mixture of $\mathrm{H}_{2}$ and $\mathrm{CO}$, is then converted to hydrocarbons by the FTS. The simplified reaction equation is presented in Equation 2.

$$
2 \mathrm{n} \mathrm{H}_{2}+\mathrm{nCO} \rightarrow \mathrm{n}(\mathrm{CH})_{2}+\mathrm{n} \mathrm{H}_{2} \mathrm{O} \quad \Delta_{\mathrm{R}} \mathrm{H}^{0}=-161 \mathrm{~kJ} / \mathrm{mol}
$$

The FTS is a highly exothermic reaction that mainly produces aliphatic hydrocarbons with a chain length of up to 100 carbon atoms. The chain length distribution varies depending on the reaction conditions as described in the introduction. The low temperature FTS, which is applied in this concept, is usually performed at $200-240{ }^{\circ} \mathrm{C}, 15-30$ bar with cobalt as catalyst. Depending on the chain growth, about $10 \mathrm{wt} .-\%$ of the products are gaseous hydrocarbons with a carbon number of 1 to 4 (i.e., methane to butane) and 90 wt.-\% of the products are liquid or solid hydrocarbons with carbon numbers ranging from 5 to about 100 .

The compact plant concept (see Figure 1) presented here offers several benefits over conventional technology. Firstly, the RWGS reaction is performed at the same pressure level as the FTS. This enables energy efficient recycling of offgas of the FTS back to the RWGS reactor. Unconverted syngas is thereby refed to the system and the gaseous hydrocarbons are reformed (steam and dry reforming of hydrocarbons) to syngas at the conditions present in the RWGS reactor. In principle, this allows a recycle rate close to $100 \%$ and consequently a yield of liquid and solid hydrocarbons close to $100 \%$, if no inert gases such as $\mathrm{N}_{2}$ are introduced to the system. Secondly, the FTS is performed using micro structured fixed bed reactors with intensified heat and mass transfer ${ }^{6}$. By performing the reaction in a micro fixed bed, the Fischer-Tropsch process becomes flexible. Start and stop of the reaction as well as load changes can be performed in the range of minutes, which is a necessity if the feed is subject to fluctuations of renewable energy production. Furthermore, the optimized heat removal by the micro structured reactor offers high selectivity towards long chain hydrocarbons and low C4- selectivity by ensuring isothermal temperatures within the catalyst bed. Lastly, water is used for evaporation cooling in cross current flow within the FTS reactor. Hence, energy rereleased in form of reaction heat can be easily recovered from the 
high temperature and pressure steam $\left(220-240{ }^{\circ} \mathrm{C}\right.$ and $23-33$ bar) available as a secondary product of the FTS reactor.

\subsection{Production of liquid product samples}

The liquid product samples were produced with a laboratory pilot plant at IMVT (KIT) that was assembled to validate the Power-to-Liquid concept described in chapter 2.1. A detailed description of the pilot plant and the synthesis procedure is given in the supplementary information. The samples were produced through coupling of RWGS and FTS reaction over a period of several days. Through staged product condensation the liquid and solid products had a mass distribution of $50 \mathrm{wt} .-\%$ light oil (C4 - C20), $30 \mathrm{wt} .-\%$ middle distillate (C9 - C30) and $20 \mathrm{wt} .-\%$ wax. The light fraction was analyzed for its applicability as a synthetic kerosene blending component, as described in the following sections.

\section{Fuel characterization and discussion}

The Fischer-Tropsch fuel ("FT Light"), synthesized in the plant of Ineratec, was investigated for its application potential as blending component for conventional aviation fuels. This feasibility study is supported by experimental investigation regarding physical, chemical and combustion properties. The present study focusses on the aspect of combustion behavior of the fuel only. Properties limiting the combustion behavior have been identified, assessed and used as input parameter for determining the potential blending ratios of the fuels.

According to ASTM D4054 a new fuel has to be evaluated against typical response or values of approved petroleum-derived jet fuels in use, as given in the World Fuel Sampling Program of the CRC (Coordinating Research Council) Aviation Committee and the CRC Handbook of Aviation Fuel Properties ${ }^{42-43}$. Based on the determined "fit for purpose" properties of the new aviation fuel, an ASTM report can be created that has to be reviewed and approved by the original equipment manufacturers (OEM) committee, which includes major aviation turbine manufacturers like GE, Rolls-Royce or Pratt \& Whitney that have strong development collaborations with aviation manufacturing companies such as Boeing or Airbus ${ }^{44}$. This balloting process of the OEM committee also decides on the incorporation of new ASTM specifications based on the report findings. The ASTM certification process for synthetic fuels is a very elaborate process, in which the fuel is tested in engine ground measurements and component rigs to ensure the compatibility with commercial turbines and fuel infrastructure/equipment. The standard-setting approach however is very conservative and 
aimed towards conventional jet fuels. The CRC data sources as used at the moment provide excellent guidance for typical physicochemical properties and temperature functions, however more recent surveys such as listed in the Petroleum Quality Information System's (PQIS) database demonstrate that they do not define the limits of experimental fuel findings and point out that many synthetic fuels will fall outside the CRC world fuel sampling program study while still being applicable ${ }^{45-46}$. As stated by the IATA, addition of further annexes to ASTM D7566 are expected as new synthetic jet fuel types are approved and with some fuels being similar to FSJF, blending with conventional jet fuels might not be necessary at all ${ }^{47}$.

Exploring the comprehensive "fit for purpose" properties as mandatory within the ASTM approval process requires a significant amount of fuel that is scarcely available from the pilot plant at the present state. For this reason the present work is focused on the combustion properties of the FT fuel as well as the related thermophysical properties. Therefore selected properties are compared to those of ASTM D4054 (referring to CRC world fuel survey) and other FT SPKs, which have already been approved as blending components. Discussion is divided into chemical composition, physiochemical properties and combustion chemistry.

\subsection{Chemical composition}

The composition of FT Light was accessed via GC-MS, detailed procedure information is given in the supporting information. Figure 2 illustrates the composition of FT Light in comparison to three other Fischer-Tropsch SPKs (Sasol IPK, Shell GTL and Sasol GTL-2) derived from synthesis gas that have already been applied as aviation blending components and were investigated in depth by Moses et al. ${ }^{48}$. 

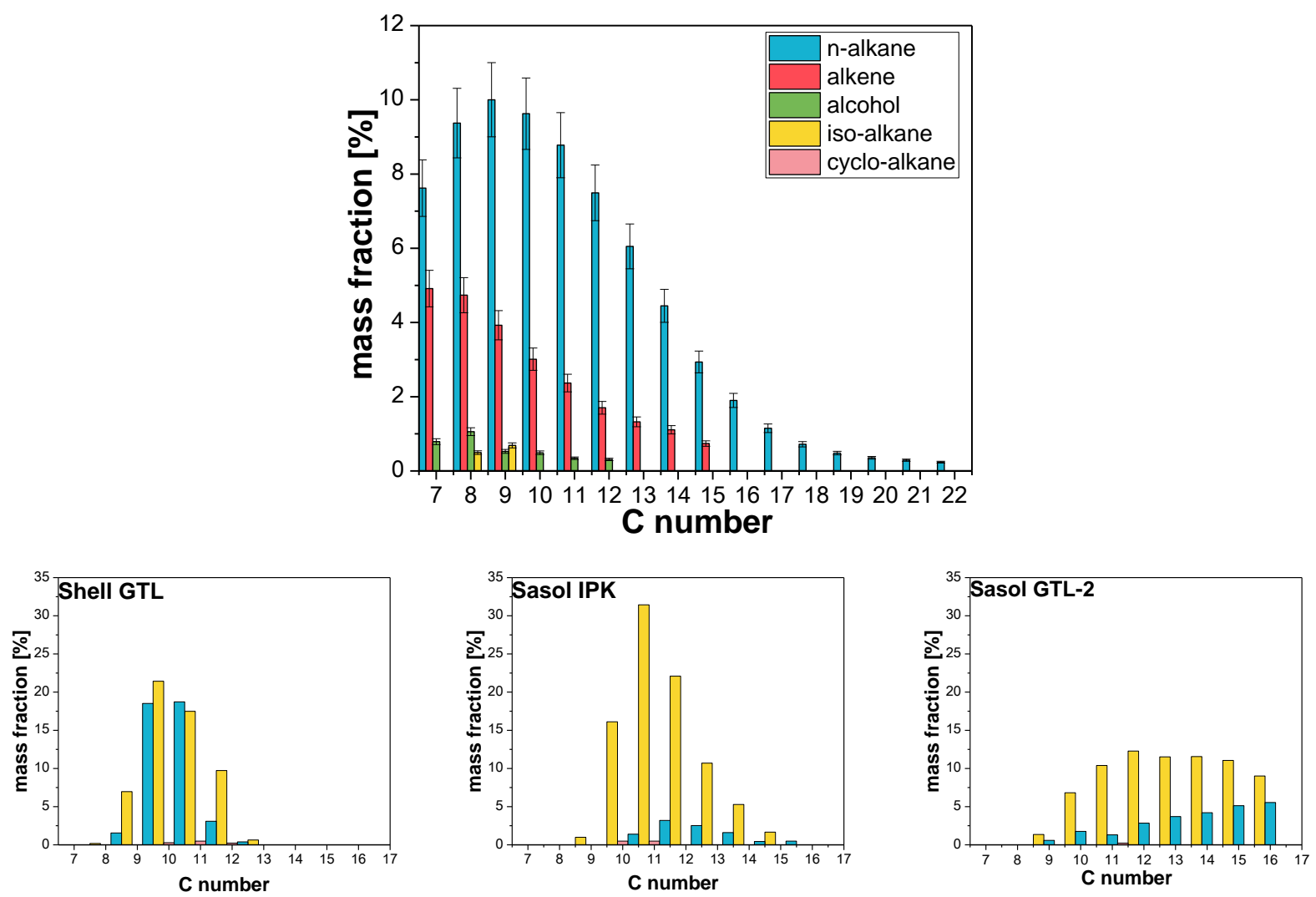

Figure 2: Composition of FT Light as determined by GCMS in comparison to three other Fischer-Tropsch SPKs: Sasol IPK, Shell GTL and Sasol GTL-2 ${ }^{9}$.

The main component of FT Light are n-alkanes at $71.5 \%$. The alkane distribution follows therein a typical Gaussian-like product distribution curve for Fischer-Tropsch products ${ }^{49}$, with the maximum peak being set at n-nonane. This product distribution is expected for Fischer-Tropsch synthesis and has already been described in the 1970s with identifying $n$ alkanes, alkenes and, in smaller amounts, oxygenated species as the main products ${ }^{50}$. The molecular weight distribution is given by the Anderson-Schulz-Flory equation with the probability for the maximum peaks being dependent on the applied catalyst and on the retention times on the catalyst, which are defined by the space velocity of the synthesis gas feed $^{51-52}$. 
Uncertainty estimation of the product distribution curves is set at a relative error of $10 \%$ which follows from subsequent repetition recovery experiments with the external standard solution. The overall composition is determined as follows: $71.47 \%$ n-alkanes, $23.83 \%$ alkenes, $3.52 \%$ alcohols and $1.18 \%$ iso-alkanes. The $\mathrm{H} / \mathrm{C}$ ratio of FT Light is given at 2.13 , the $\mathrm{O} / \mathrm{C}$ ratio at only 0.15 . Determination was carried out via the $\mathrm{GC}$ analysis and confirmed by hydrogen content NMR analysis using a Bruker minispec mq-one Hydrogen Analyzer. The $\mathrm{H} / \mathrm{C}$ makes it furthermore obvious that FT Light contains no aromatics in relevant amounts since the $\mathrm{H} / \mathrm{C}$ ratio is usually used synonymously with the total aromatic content of the fuel ${ }^{3}$, 53. High amounts of oxygenated species are not desired for aviation purposes due to their lower energy release during combustion and their water retention potential. FT Light contains in particular $3.52 \%$ alcohols, however these alcohols are all longer chained monoalcohols (C7-C12), therefore bringing the overall oxygen content to only $0.34 \%$ as can be seen in Table 1.

Table 1: Chemical composition of FT Light divided up by elements.

\begin{tabular}{ll}
\hline Element & Content [mass\%] \\
\hline carbon & 84.54 \\
hydrogen & 15.12 \\
\hline oxygen & 0.34 \\
\hline
\end{tabular}




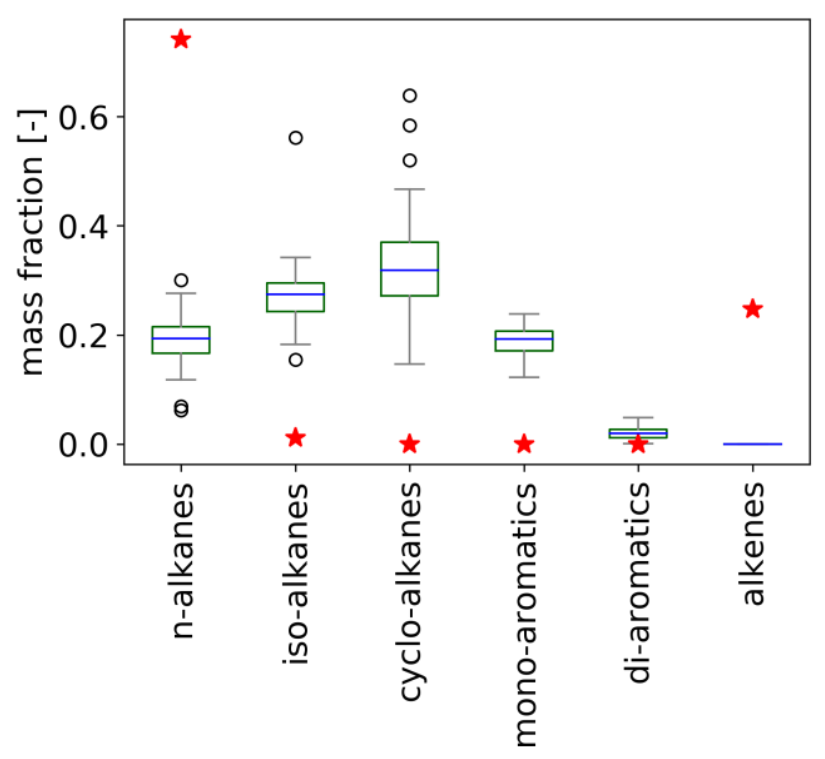

Figure 3: Composition of FT Light in comparison to CRC fuels (alcohols are neglected). Boxplots show the statistical distribution of the CRC fuels, open circles are outliers: Box includes the range $1^{\text {st }}$ to $3^{\text {rd }}$ quartile, the blue band being the median. Whiskers show the lowest mass fraction still within 1.5 the interquartile range (IQR) from the lower quartile and the highest mass fraction still within 1.5 IQR of the upper quartile, respectively. FT Light is represented by red stars.

Figure 3 shows the variation of the composition of the CRC fuels ${ }^{42}$ for the fuel families nalkanes, iso-alkanes, cyclo-alkanes, mono-aromatics, di-aromatics and alkenes with boxplots. Open circles show outliers. The composition of FT Light is highlighted with the star-symbols. It is clearly visible, that the composition of FT Light differs from the conventional jet fuels. Alcohols are not shown in Figure 3.

\subsection{Fuel properties}

The determined physicochemical properties of the selected "fit for purpose" properties are given in

Table 2. The properties have been selected with respect to aviation purposes as given and discussed in the CRC Handbook of Aviation Fuel Properties ${ }^{43}$ and the CRC World Fuel Sample Program $^{42}$. Bulk physical and performance properties such as density or viscosity for 
example are crucial for aircraft and engine design or the calculation of pressure drops in fuel systems design.

Table 2: Selected physiochemical properties of FT Light with hindsight to the relevant ASTM norms D1655/D4054.

\begin{tabular}{|c|c|c|c|}
\hline Fuel property & Value & Test method & CRC jet fuel range* \\
\hline \multicolumn{4}{|c|}{ BULK PHYSICAL AND PERFORMANCE PROPERTIES } \\
\hline Density $\left(-20^{\circ} \mathrm{C}\right)$ & $761.7 \mathrm{~kg} / \mathrm{m}^{3}$ & ASTM D7042 & $813-851 \mathrm{~kg} / \mathrm{m}^{3}$ \\
\hline $\begin{array}{l}\text { Density }\left(15^{\circ} \mathrm{C}\right) \\
\text { (interpolated) }\end{array}$ & $734.9 \mathrm{~kg} / \mathrm{m}^{3}$ & ASTM D7042 & $788-825 \mathrm{~kg} / \mathrm{m}^{3}$ \\
\hline Density $\left(20^{\circ} \mathrm{C}\right)$ & $731.1 \mathrm{~kg} / \mathrm{m}^{3}$ & ASTM D7042 & $782-821 \mathrm{~kg} / \mathrm{m}^{3}$ \\
\hline Density $\left(60^{\circ} \mathrm{C}\right)$ & $699.5 \mathrm{~kg} / \mathrm{m}^{3}$ & ASTM D7042 & $752-790 \mathrm{~kg} / \mathrm{m}^{3}$ \\
\hline $\begin{array}{l}\text { Kin. Viscosity } \\
\left(-40^{\circ} \mathrm{C}\right)\end{array}$ & $10.06 \mathrm{~mm}^{2} / \mathrm{s}$ & ASTM D7042 & $4,9->12 \mathrm{~mm}^{* * 2} / \mathrm{s}$ \\
\hline $\begin{array}{l}\text { Kin. Viscosity } \\
\left(-20^{\circ} \mathrm{C}\right)\end{array}$ & $2.502 \mathrm{~mm}^{2} / \mathrm{s}$ & ASTM D7042 & $2,6-6,0 \mathrm{~mm}^{2} / \mathrm{s}$ \\
\hline $\begin{array}{l}\text { Kin. Viscosity } \\
\left(25^{\circ} \mathrm{C}\right)\end{array}$ & $1.178 \mathrm{~mm}^{2} / \mathrm{s}$ & ASTM D7042 & $1,25-2,0 \mathrm{~mm}^{2} / \mathrm{s}$ \\
\hline $\begin{array}{l}\text { Kin. Viscosity } \\
\left(40^{\circ} \mathrm{C}\right)\end{array}$ & $0.981 \mathrm{~mm}^{2} / \mathrm{s}$ & ASTM D7042 & $0,98-1,5 \mathrm{~mm}^{2} / \mathrm{s}$ \\
\hline
\end{tabular}




\begin{tabular}{lccc}
\hline Heating value & $\begin{array}{c}43.7524 \\
\mathrm{MJ} / \mathrm{kg}\end{array}$ & ASTM D240 & $>42,8 \mathrm{MJ} / \mathrm{kg}$
\end{tabular}

*"typical response or values within engine/airframe manufacturers' experience", relating to CRC specification limits ${ }^{43,54 * *}=$ design limit for engine starting: $12 \mathrm{~mm}^{2} / \mathrm{s}$

Oxygenated species are not desired for aviation purposes due to their lower energy release during combustion and their water retention potential. FT Light contains in particular $3.52 \%$ alcohols, however these alcohols are all longer chained monoalcohols (C7-C12), therefore bringing the overall oxygen content to only $0.34 \%$. The heating value of FT Light is with around $43.75 \mathrm{MJ} / \mathrm{kg}$ above the minimal requirement of $42.8 \mathrm{MJ} / \mathrm{kg}$ as set by the ASTM D1655, falling in line with other reported FT SPK heating values around approx. $44 \mathrm{MJ} / \mathrm{Kg}^{9}$ and demonstrating that the minor oxygen content of FT Light is not a drawback in terms of combustion. However, minimizing the alcohol content is necessary and a target of further process optimization due to its water retention potential.

It has been demonstrated by Moses et al. and others before that Fischer-Tropsch SPKs display in general densities and kinematic viscosities significantly below the ASTM specification limits due to their high amount of medium sized alkanes and absence of aromatics $^{48,55}$. Therefore it is conclusive that FT Light also falls in to that range: FT Light displays a density of $734.9 \mathrm{~kg} / \mathrm{m}^{3}$ at $15{ }^{\circ} \mathrm{C}$, being similar to those of Sasol GTL-1 at $733.3 \mathrm{~kg} / \mathrm{m}^{3}$ of Shell GTL at $736.1 \mathrm{~kg} / \mathrm{m}^{3}$. Sasol GTL-2 and Sasol IPK display higher densities of $761.6 \mathrm{~kg} / \mathrm{m}^{3}$ and $768.8 \mathrm{~kg} / \mathrm{m}^{3}$ respectively (linked to their higher iso-alkane amount) but still fall below the Jet $A / J$ et A-1/JP-8 CRC minimum of $775.0 \mathrm{~kg} / \mathrm{m}^{343}$.

Due to not being hydrotreated, FT Light contains at $23.8 \%$ a significantly higher amount of alkenes than other FT SPKs, which contain no or only trace amounts of alkenes ${ }^{9,56}$. What has to be taken into consideration concerning the alkene content is the overall oxidation and storage stability of FT Light. As in the present publication only combustion properties were regarded, future studies have to focus on performing tests and optimizing fuel storage stability.

In addition to the determined fuel properties in Table 2, distillation curves are regarded as sensitive property for fuel characterization ${ }^{43}$. ASTM D4054 gives therein exact specifications for the recovered volumes at defined temperatures. Experimental distillation and simulated distillation via GC-MS was performed for FT Light, more information on the experimental set-up is provided in the supporting information. 


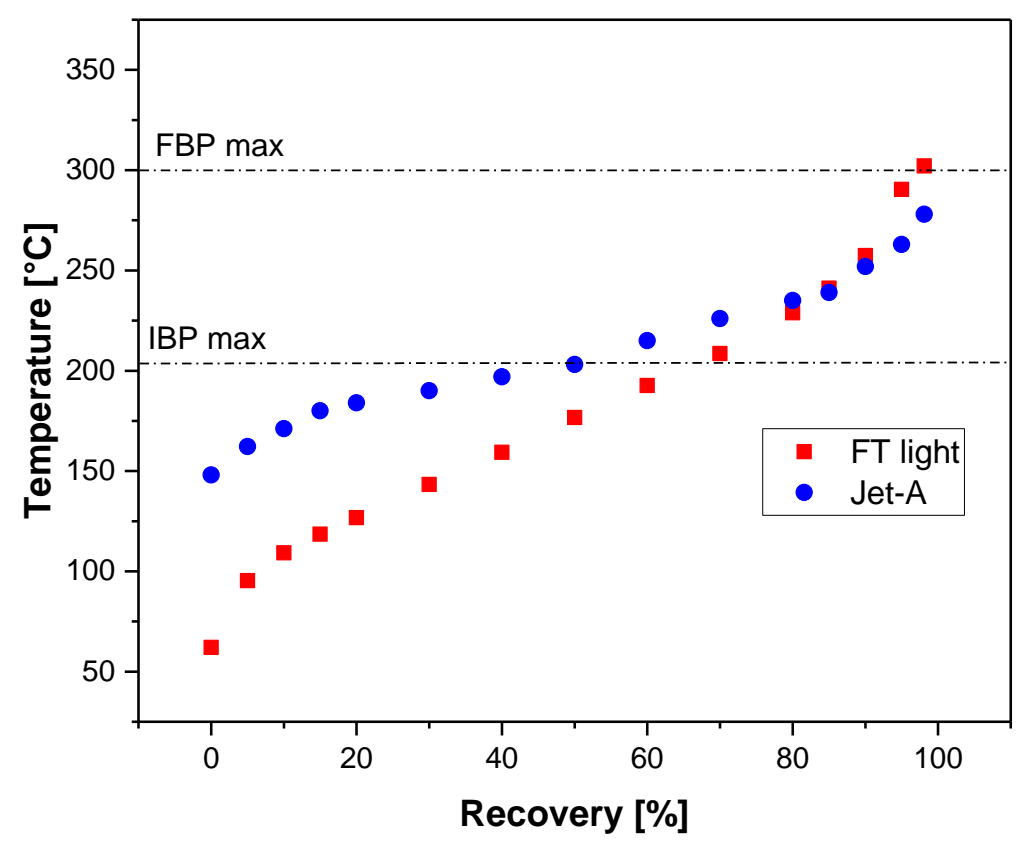

Figure 4: Experimental distillation curves of FT Light in comparison to a typical Jet A-1 fuel ${ }^{57}$.

The experimental and simulated distillation results are shown in Table 3 with the respective ASTM specifications. The deviations found between experimental validation and simulated results are in the expected regime.

Table 3: Experimental vs. simulated distillation properties of FT Light.

\begin{tabular}{|c|c|c|c|}
\hline $\begin{array}{l}\text { Boiling point } \\
\text { distribution }\end{array}$ & $\begin{array}{l}\text { Experimental } \\
\text { distillation }\left[{ }^{\circ} \mathrm{C}\right] \\
\text { (ASTM D86) }\end{array}$ & $\begin{array}{l}\text { Simulated } \\
\text { distillation }\left[{ }^{\circ} \mathrm{C}\right] \\
\text { (ASTM D2887) }\end{array}$ & ASTM specification \\
\hline Initial Boiling Point & 62.03 & 82.70 & $\begin{array}{l}\max .205^{\circ} \mathrm{C} \\
\mathrm{D} 4054 / \mathrm{D} 7566 / \mathrm{D} 1655\end{array}$ \\
\hline $\begin{array}{l}10 \% \text { Recovery } \\
(\mathrm{T} 10)\end{array}$ & 109.21 & 116.20 & $\begin{array}{l}\min .150^{\circ} \mathrm{C} / \max .205^{\circ} \mathrm{C} \\
\mathrm{D} 4054\end{array}$ \\
\hline $\begin{array}{l}50 \% \text { Recovery } \\
(\mathrm{T} 50)\end{array}$ & 176.66 & 174.60 & $\begin{array}{l}\min .165^{\circ} \mathrm{C} / \max .229^{\circ} \mathrm{C} \\
\mathrm{D} 4054\end{array}$ \\
\hline
\end{tabular}




\begin{tabular}{|c|c|c|c|}
\hline $\begin{array}{l}90 \% \text { Recovery } \\
(\mathrm{T} 90)\end{array}$ & 257.45 & 246.10 & $\begin{array}{l}\min .190^{\circ} \mathrm{C} / \max .262^{\circ} \mathrm{C} \\
\mathrm{D} 4054\end{array}$ \\
\hline Final Boiling Point & 302.06 & 294.50 & $\begin{array}{l}\max .300{ }^{\circ} \mathrm{C} \\
\mathrm{D} 4054 / \mathrm{D} 7566 / \mathrm{D} 1655\end{array}$ \\
\hline T50 - T10 & 67.45 & 58.4 & $\begin{array}{l}\min 15^{\circ} \mathrm{C} \\
\mathrm{D} 4054\end{array}$ \\
\hline T90 - T10 & 148.24 & 178.3 & $\begin{array}{l}\min .40^{\circ} \mathrm{C} \\
\mathrm{D} 4054\end{array}$ \\
\hline $\begin{array}{l}\text { Distillation residue } \\
\%\end{array}$ & $1.1 \%$ & - & $\begin{array}{l}\max .1,5 \% \\
D 1655\end{array}$ \\
\hline
\end{tabular}

The initial boiling point (IBP) was at $62.0^{\circ} \mathrm{C}$ well below the maximal initial boiling point as given by the ASTM D1655. The maximal final boiling point (FBP) was exceeded slightly with $302.1{ }^{\circ} \mathrm{C}$ (FBP $\max$ ASTM D1655: $300{ }^{\circ} \mathrm{C}$ ) for the experimental distillation. These values however will need to fall into the specified range when the resulting blend with regular Jet fuel is considered (see chapter 3.4). Experimental and simulated distillation differ which is a known phenomenon due to the different determination methods and can be converted into each other using the Riazi-Daubert method ${ }^{58-59}$.

\subsection{Combustion chemistry}

Combustion properties were investigated by the DLR high temperature flow reactor with coupled molecular beam mass (MBMS) spectrometer ${ }^{60}$. This experimental system is capable for in-depth investigation of the combustion chemistry with respect to main reaction channels and intermediate species formation in the combustion process of various fuels. Comparison of quantitative species profiles allows for estimation of reactivity and the fuel influence on emissions of technical combustors. Fuel supply covers the range from simple gaseous species (e.g. methane) to complex liquid fuels mixtures (e.g. technical fuels like Jet A-1). Since comprehensive recent literature on the applied experimental setup is available ${ }^{60-}$ ${ }^{64}$, only a brief description is given here.

The system can be divided into two segments: first, the high temperature laminar flow reactor including gas supply and vaporizer system and second, a molecular beam mass spectrometry (MBMS) time-of-flight detection (TOF) system. The reactor exit is positioned to the sampling nozzle of the MBMS-TOF system and gas is sampled directly from the reactor outlet and transferred to the high-vacuum detection system. 
The reactor itself features an alumina $\left(\mathrm{Al}_{2} \mathrm{O}_{3}\right)$ ceramic tube $(40 \mathrm{~mm}$ inner diameter, total length of $1497 \mathrm{~mm}$ ), where premixed laminar flowing gases are fed highly diluted ( 99 \% Ar) into the reactor. High dilution suppresses heat release and a self-sustaining reaction. Boundary effects are minimized by the reactor design with dimensions including relatively large inner diameter. The vaporizing system is a commercial setup (Bronkhorst, CEM) with a pneumatically driven fuel supply equipped with a Coriolis flow meter (Bronkhorst, Mini CoriFlow M12). All input streams are metered in high precision (accuracy $\pm 0.5 \%$ ) by Coriolis mass flow meters. Complete evaporation was ensured by the small fuel fraction and the low partial pressure (typically below $100 \mathrm{~Pa}$ ) needed. Experimental inlet flow conditions are listed in Table 4. Conditions are designed to yield constant carbon flow at slightly rich and lean conditions respectively. Stoichiometric conditions may be interpolated since exact adjustment of $\Phi=1.0$ can be difficult due to the experimental uncertainty in the fuel composition.

Table 4: Reactor initial conditions for FT Light, $9900 \mathrm{sccm}$ (standard cubic centimeter per minute at $1013 \mathrm{mbar}, 273 \mathrm{~K}$ ) argon are added as diluent for all measurements.

\begin{tabular}{cccc}
\hline$\phi$ & $\begin{array}{c}\text { Fuel (gas) } \\
\text { (sccm) }\end{array}$ & $\begin{array}{c}\mathbf{O}_{\mathbf{2}} \\
\text { (sccm) }\end{array}$ & $\begin{array}{c}\text { Fuel (liquid) } \\
\text { (mg/min) }\end{array}$ \\
\hline $\mathbf{0 . 8}$ & 5.00 & 96.7 & 31.7 \\
$\mathbf{1 . 2}$ & 5.00 & 64.4 & 31.7 \\
\hline
\end{tabular}

The premixed gases are fed into the reactor by a tempered flange equipped with a porous bronze plug to create homogeneous flow conditions. The reaction segment has a total length of $1000 \mathrm{~mm}$, heated by a customized high temperature oven (Gero, Type HTRH 40-1000) capable of temperatures up to $1900 \mathrm{~K}$. Gases were sampled at the reactor exit, transferred to high vacuum $\left(10^{-4} \mathrm{~Pa}\right)$ by a two-stage differential pumping system and finally detected by an electron impact (EI) time-of-flight (TOF) mass spectrometer (Kaesdorf, mass resolution $\mathrm{R}$ = 3000). The MBMS-TOF system is capable to determine the elemental composition of combustion intermediates within a $\mathrm{C} / \mathrm{H} / \mathrm{O}$ system. To avoid species fragmentation at the ionization process, soft electron energies are applied. Additionally, a residual gas analyzer (RGA), i.e. a quadrupole mass spectrometer, was placed in the ionization chamber and operated at a higher electron energy $(70 \mathrm{eV})$ allowing for tracking those major species simultaneously to the MBMS-TOF measurements. Details on the experimental setup, including schematic and its instrumentation may be found in previous publications ${ }^{60,63}$. 
The measurements were performed at constant inlet mass flow with a monotonically decreasing temperature $\operatorname{ramp}(-200 \mathrm{~K} / \mathrm{h})$ applied to the oven. The typical temperature range $1.200 \mathrm{~K}$ to $600 \mathrm{~K}$ covers the regime from unreacted fuel to full conversion to thermal equilibrium as it also occurs in common combustion processes. The simple flow conditions allows for observation of chemical reactions without interaction with a complex flow field and are even well suited for comparison with zero dimension (i.e. plug flow) kinetic model calculations and model development ${ }^{60,65}$.

Signals were quantified following well established methods described in previous publications ${ }^{66-67}$ by direct binary (species/Ar) calibration measurements or estimation of the ionization cross section based on the RICS (relative ionization cross section) method ${ }^{68}$. Calibration by direct cold gas measurements was performed for the species discussed herein. A detailed description of the DLR high temperature flow reactor setup, the measurement procedure, the experimental characterization and the data evaluation including uncertainty analysis is provided in the elaborate references and respective supplemental material ${ }^{60,63,66}$.

The obtained mole fractions of the major species in combustion are plotted versus the oven temperature, which can be interpreted as kind of reaction progress, for the lean and rich condition in Figure $5 \mathrm{~A}$ and $5 \mathrm{~B}$. Fuel and $\mathrm{O}_{2}$ are consumed with increasing temperature, while $\mathrm{CO}_{2}$ and $\mathrm{H}_{2} \mathrm{O}$ are formed as main products. Note that even through the temperature range is matching, no low temperature chemistry like an NTC behavior can be observed at the present conditions due to the short residence time ${ }^{69}$. This reaction regime is in principle also accessible with the present setup but is, however, not of crucial importance for gas turbine combustion $^{70}$. With respect to technical fuels, Jet $\mathrm{A}-1$ is shown in Figure $5 \mathrm{C}$ featuring identical slope as the FT Light. The similarity to the major speciation profiles of $n$-decane as representative $n$-alkane is noteworthy for the same stoichiometry of 0.8 as shown in Figure $5 \mathrm{D}$, indicating a similar global combustion chemistry behavior.

In-depth comparison of the ignition temperature, however, reveals distinct differences. "Ignition" occurs, when $\mathrm{O}_{2}$ and the fuel exhibit their steepest reduction in concentration and $\mathrm{CO}_{2}$ and $\mathrm{H}_{2} \mathrm{O}$ exhibit their steepest increasing gradient. Comparing the 0.8 stoichiometries, the lowest ignition temperature is observed for the FT Light with $1013 \mathrm{~K}$, the highest for Jet A-1 with $1037 \mathrm{~K}$ and $\mathrm{n}$-decane close to FT Light with $1018 \mathrm{~K}$. Reasons for the ignition delay can be explained by taking the chemical composition into account: with $71.5 \%$ n-alkanes for the FT Light, the combustion behavior seems dominated by the $n$-alkanes, while Jet A- 1 has an even lower $n$-alkane content with a $22 \%$. Other chemical classes like iso-alkanes or 
aromatic species, however, differ by 30-70 K easily, indicating a strong influence from the $\mathrm{n}$ alkane group in the FT Light being close to the class of n-alkanes. Since no hydrotreatment is applied to FT Light, all alkanes are as expected in the normal configuration in contrast to other typical FT SPK jet fuels. Shell GTL for example has a 42/58 ratio and Sasol IPK (isoparaffinic kerosene) a $2 / 98$ ratio of $n /$ iso alkanes ${ }^{48,71}$. In case of the Sasol IPK, the low $n$ /iso ratio is achieved via an additional isomerization step within the coal to liquid synthesis ${ }^{72}$. The excellent suitability of $n$-Alkanes for blending with Jet $A-1$ as has been demonstrated in several publications ${ }^{73-76}$ and is to be expected since the Jet $A$ fuels contain a relatively high amount of $n$-alkanes themselves; the Jet $A$ fuel as thoroughly studied by Bruno et al. for example consists of nearly $40 \%$ n-alkanes ${ }^{77}$. The high n-alkane content of FT Light is greatly relevant in respect of ignition delay times, since the ignition delay times of FT SPKs depend on the $\mathrm{n}$ /iso ratio as could be demonstrated in a study on the combustion characteristics of FT SPK jet fuels by Hui et al. ${ }^{78}$ It could be confirmed, that the ignition delay times where significantly shorter for a high n/iso ratio, with Shell GTL (2.64 ms) displaying nearly half the delay time than that of Sasol IPK $(5.11 \mathrm{~ms})$. Another combustion characteristic that is sensitive to the fuel composition is the derived cetane number (DCN). Due to the high amount of reactive $n$-alkanes, the DCNs of FT Light is to be expected higher than that of Jet $A$ and Sasol IPK, since Jet A-1 contains about $20 \%$ aromatics while IPK consists mostly of isoand cyclo-alkanes; all of these compounds are less reactive compared to $\mathrm{n}$-alkanes. 


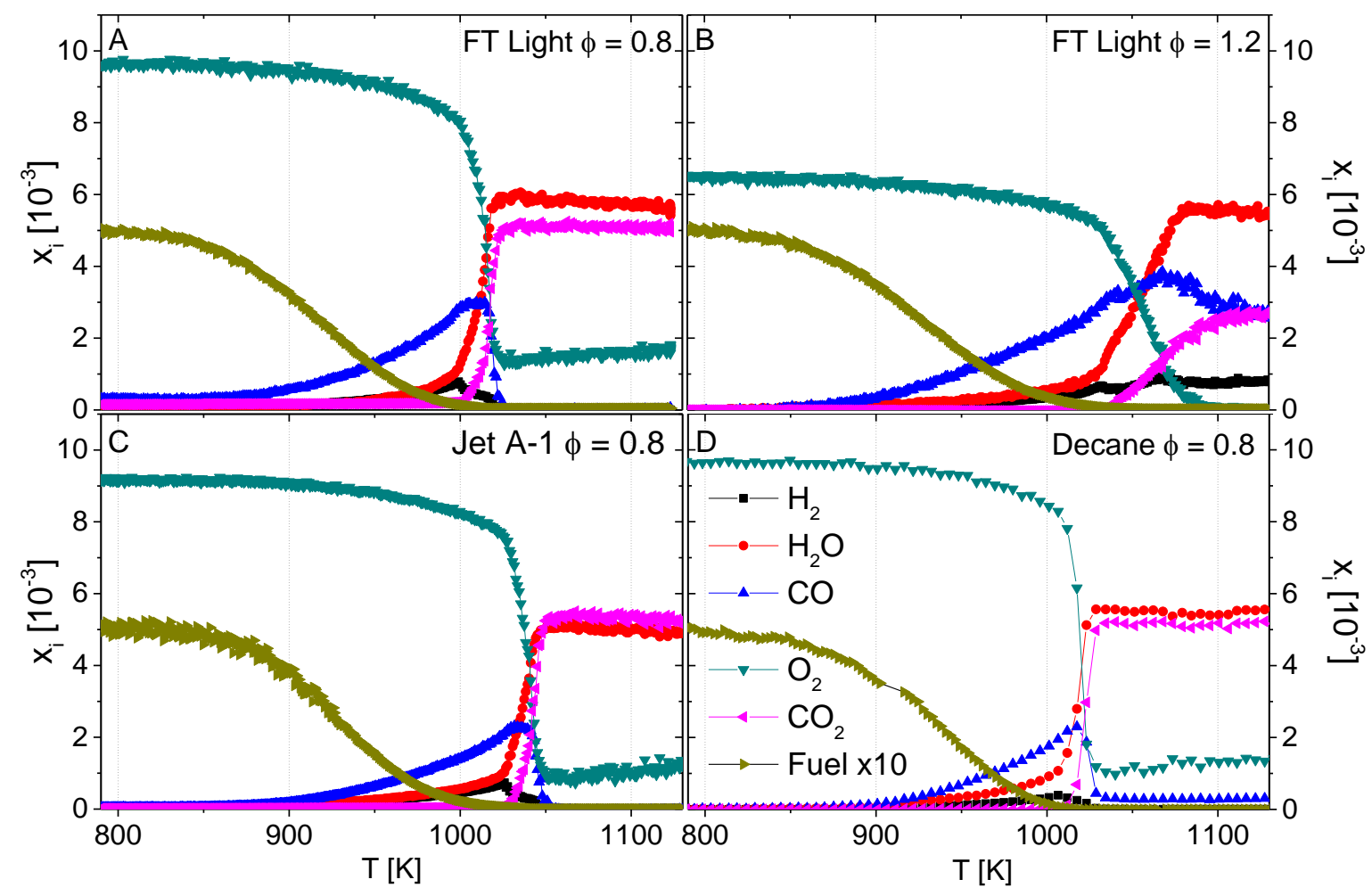

Figure 5: Mole fraction profiles for major combustion products. For complex fuels (FT Light , Jet A-1) "fuel" refers to a selected representative alkane species scaled to the initial mole fraction of the complex mixture.

Further differences become obvious when the fuel destruction is examined in detail. Figure 6 breaks the fuel decomposition of the FT Light fuel down to the individual alkane species $\left(\mathrm{C}_{n} \mathrm{H}_{2 n+2}\right)$ present in the fuel. However, the species profiles of the $n$-alkanes (Figure 6A) are found to show an almost identical shape as can be seen from the normalized profiles. Solely a small shift to lower temperatures with increasing carbon number can be considered. Figure $6 \mathrm{~B}$ gives the respective alkane profiles observed for the regular Jet $A-1$. Despite the increased experimental scatter for the alkane profiles obtained from Jet A-1 the oxidation of the statured alkane species appears to be identical in both fuels. Thus the differences in the mayor species (Figure 5) and global reactivity may be attributed to other fuel components. Indeed, a more distinct dependence of decay behavior on the carbon number can be observed for other hydrocarbon types typically present in Jet Fuels e.g. for monoaromatic species $\left(\mathrm{C}_{n} \mathrm{H}_{2 n-6}\right)$ shown in Fig $6 \mathrm{C}$. Here the $\mathrm{C} 8$ compound i.e. $\mathrm{C}_{8} \mathrm{H}_{10}$ (ethyl benzene and xylene) is even formed as an intermediate during the combustion process. 

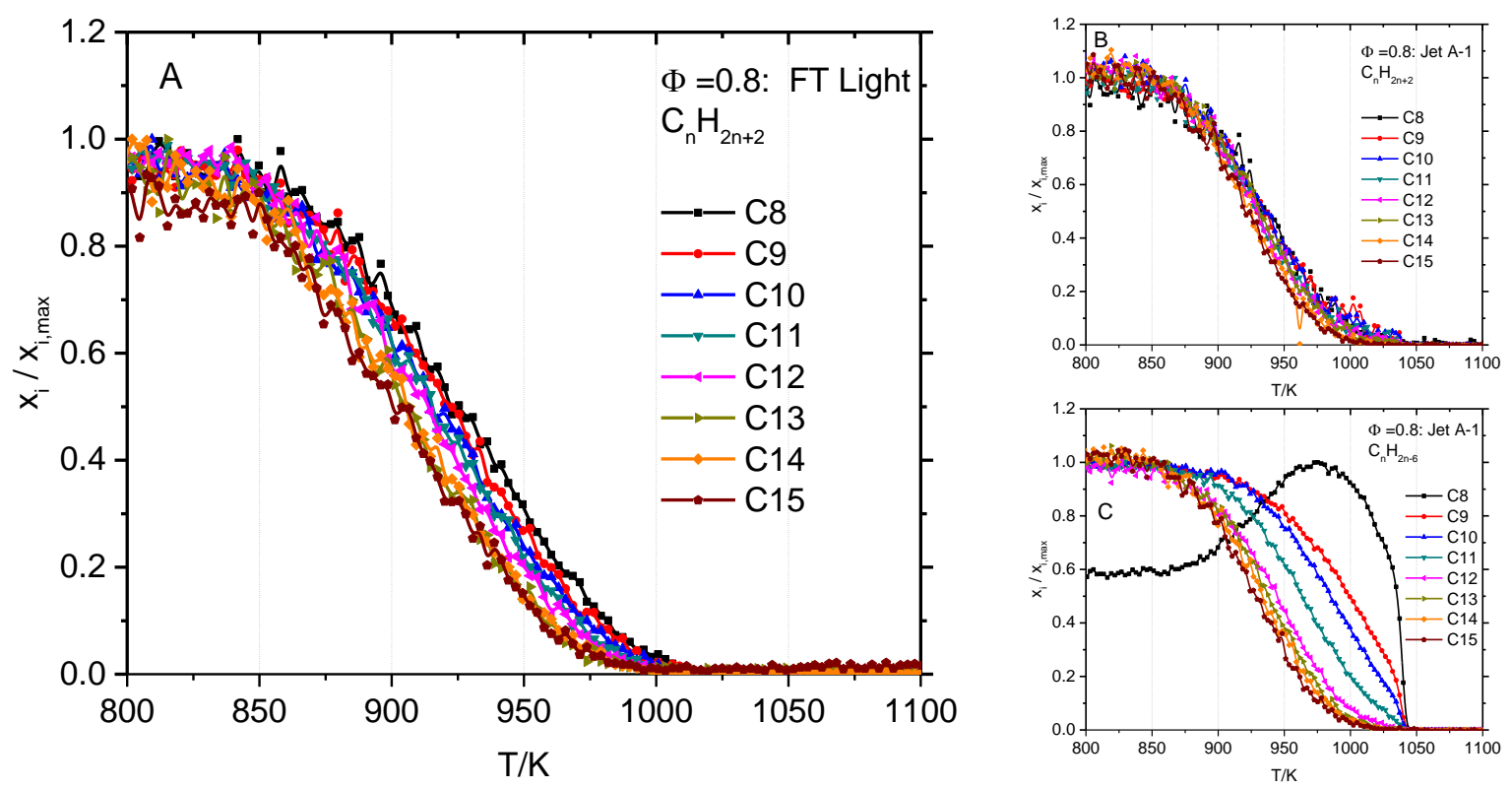

Figure 6: Normalized mole fraction profiles of fuel components: Alkanes in FT Light (A) and regular Jet A-1 (B) as well monocratic species in Jet A-1 (C).

Further distinct differences occur, when the intermediate species are taken into account. Figure 7 shows the mole fraction profiles of the aromatic soot precursors benzene $\mathrm{C}_{6} \mathrm{H}_{6}(7 \mathrm{~A})$ and naphthalene $\mathrm{C}_{10} \mathrm{H}_{8}$ (7B) for FT Light, Jet $\mathrm{A}-1$ and $\mathrm{n}$-decane stoichiometry 0.8 . For benzene, a maximum mole fraction of $3.510^{-5}$ is detected at $1030 \mathrm{~K}$, which is roughly a factor 10 higher than for the FT Light peaking at $1007 \mathrm{~K}$ with $3.710^{-6}$ and the lowest $\mathrm{n}$ decane peaking at $1015 \mathrm{~K}$ with $1.910^{-6}$. Note, while the absolute errors may range in order of $20-30 \%$, the relative error in the benzene mole fraction is less than $10 \%$. The soot precursor formation for FT Light is in the given conditions a factor of 10 lower than in Jet A1.

This is underlined by the graph in Figure 7B, showing the mole fraction profiles of naphthalene. Jet A-1 includes some naphthalene in the initial mixture and peaks as expected at the same temperature as benzene with $3.610^{-6}$ in concentration. This is significantly higher than the detected concentrations for the latter $n$-decane and FT Light, which show no intermediate profile shape at all.

This significant reduction in soot precursor species highlights the capability or reducing soot emissions from technical combustors by the means of increasing the $\mathrm{H}$-content of the fuel by blending or substitution crude oil based Jet A-1 by highly aliphatic SPKs. Pure ATJ-SPK for 
example was found to reduce emissions by $20-80 \%$ compared to regular Jet A-1 at different power settings of an CFM56 test engine ${ }^{79}$.

In addition, more than 30 intermediate species were measured. To avoid an ongoing lengthy discussion on single intermediate species and focus more on the overall goal, further discussion is omitted. However, for interested readers, the full obtained speciation data is available upon request.

In summary no significant deviation of the investigated FT Light product was observed regarding the general gas phase combustion reaction chemistry, neither in comparison to regular Jet A-1 nor to the neat $n$-decane. Simultaneous a beneficial reduction of soot precursor species compared to Jet $A-1$ is observed.

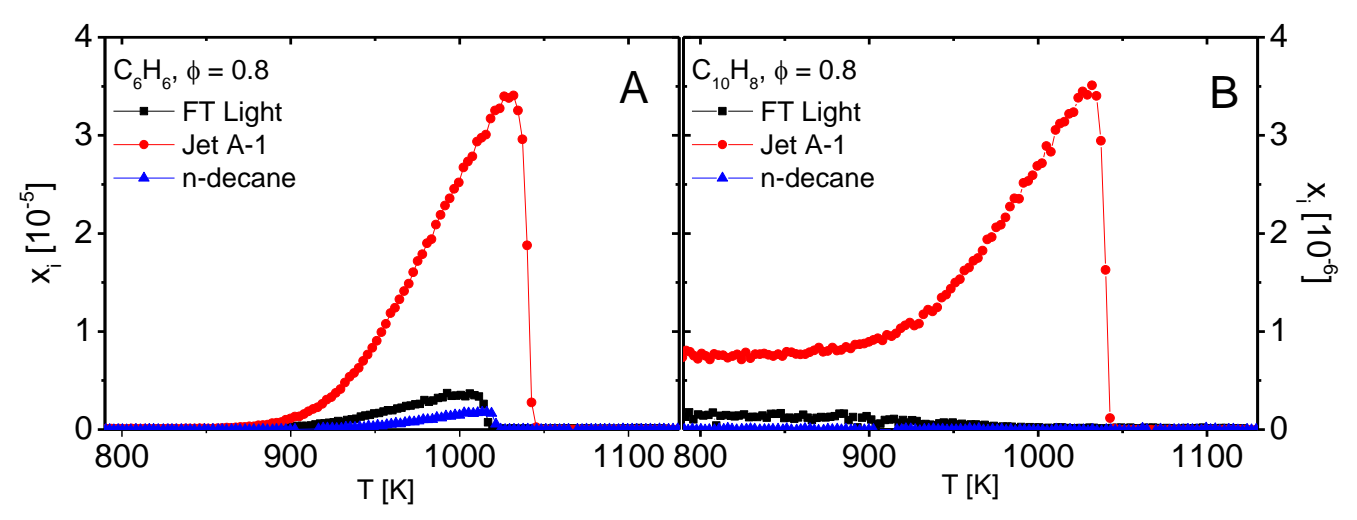

Figure 7: Mole fraction profiles of soot precursor intermediate species benzene $C_{6} \mathrm{H}_{6}(A)$ and naphthalene $C_{10} H_{8}(B)$.

\subsection{Limiting factors and blending ratios}

In this work, the neat FT Light was studied to identify the main limiting factors. Limiting factors are properties of the synthetic fuel, which are outside of the allowed specification range for the final blend and hence they are limiting the maximum blending ratio. The limiting factors influencing FT Light combustion behavior were identified in Table 5 and Table 6 as: density, aromatics content and distillation.

To be within specification, FT Light has to be blended with conventional jet fuels. However, the maximum possible blending ratio depends not only on the properties of the alternative fuel, but also on the properties of the conventional fuel that is used for blending. For the already approved hydrotreated FT-SPKs in the Annex of ASTM D7566, the maximum 
blending ratio is defined as $50 \%$. The factors limiting the blending ratio of hydrotreated FTSPKs are: density, aromatics content and distillation properties ${ }^{80}$.

The distillation behavior is a measure for the fuels evaporation behavior. The evaporation process itself plays a major role for combustion processes like ignition, lean blow-out (LBO) and unburned hydrocarbons (UHC) emissions. To understand the influence of the out-ofspec distillation properties, the effective evaporation rate of FT Light was computed at respective critical operational conditions and compared to the effective evaporation rate of the fuels of the CRC world fuel survey. The respective critical operational conditions of turbines are listed in Table 5. Table 6 summarizes operational conditions which influence emissions.

Table 5: Critical operation conditions. Bold values indicate the used values ${ }^{81}$.

\begin{tabular}{llll}
\hline No & Condition & Temperature & Pressure \\
\hline $\mathbf{1}$ & Cold Start & $238 \mathrm{~K}-350 \mathrm{~K}$ & $1 \mathrm{~atm}$ \\
$\mathbf{2}$ & High Altitude Relight & $238 \mathrm{~K}$ & $\mathbf{0 . 3 8} \mathrm{atm}$ \\
$\mathbf{3}$ & Lean Blow-out & $400 \mathrm{~K}-450 \mathrm{~K}$ & $\mathbf{2} \mathrm{atm}-4 \mathrm{~atm}$ \\
\hline
\end{tabular}

Table 6: Operational conditions influencing emissions. Bold values indicate the used values ${ }^{82}$.

\begin{tabular}{llll}
\hline No & Condition & Temperature & Pressure \\
\hline 4 & Idle (UHC) & $400 \mathrm{~K}$ & $2.73 \mathrm{~atm}$ \\
5 & Cruise (UHC) & $620 \mathrm{~K}$ & $7.8 \mathrm{~atm}$ \\
6 & Takeoff (UHC) & $715 \mathrm{~K}$ & $17.4 \mathrm{~atm}$ \\
\hline
\end{tabular}

For conditions 1, 3, 4 and 5 in Table 5 and Table 6 the effective evaporation rate

$$
\lambda_{\text {eff }}=\frac{D_{0}{ }^{2}}{t_{\text {evap }}}
$$

of a single droplet is computed using the Abramzon-Sirignano type vaporization model implemented in the DLR spray code SPRAYSIM ${ }^{83}$. The composition-dependent multi- 
component vaporization is realized with the continuous thermodynamics model $(C T M)^{84}$. $D_{0}$ is the initial droplet diameter and $t_{\text {evap }}$ is the time needed for full evaporation of the droplet. During high altitude relight, the process of evaporation is strongly coupled and influenced by the external ignition spark. This means that evaporation at $238 \mathrm{~K}$ and $0.38 \mathrm{~atm}$ is not the major process describing ignition and therefore high altitude relight is not considered in the present study. During takeoff, flash boiling might occur. Since this process is not yet included in our model, takeoff condition is also not considered in this study.

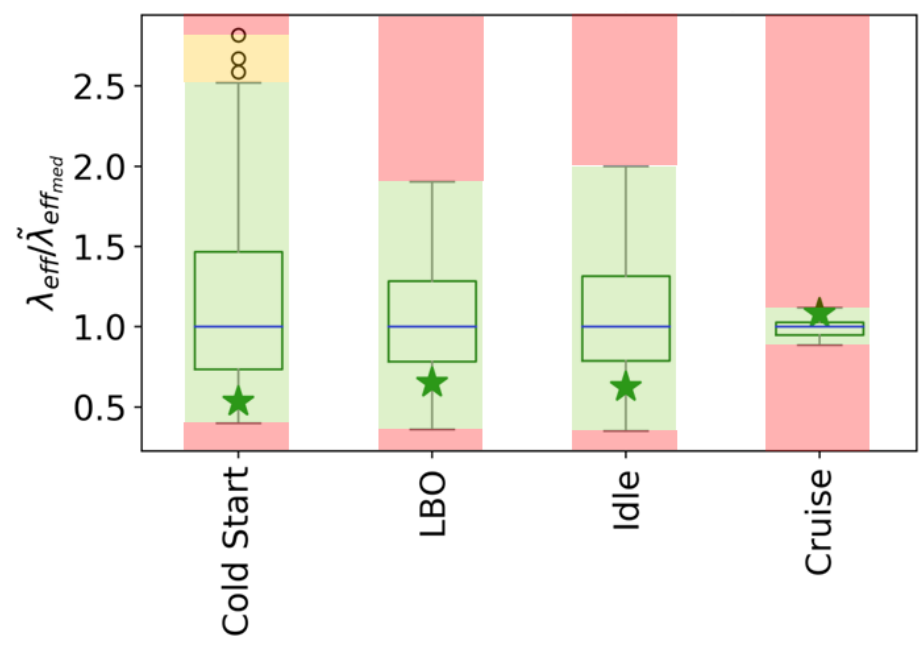

Figure 8: Relative effective single droplet evaporation rate of FT Light (green star symbols) in comparison to CRC fuels (statistical representation of the results by boxplots; open circles represent statistical outliers) for different operation conditions. (Green color indicates values within range of experience, yellow indicates the outlier region and red indicates values out of experience.)

In Figure 8, the effective evaporation constant of FT Light is compared to the effective evaporation constant of the CRC fuels for the four critical operational conditions cold start(1), LBO(3), idle(4) and cruise(5). The evaporation behavior of FT Light is outside the box of the boxplot, meaning outside the middle $50 \%$ of evaporation rates, but always within the range of evaporation rates of the conventional CRC fuels for all four operational conditions. This indicates that the distillation is not the most critical property regarding the combustion behavior. Hence, the evaporation of FT Light is not regarded as a limiting factor for combustion in this paper. It has to be noted that a potential FT Light would have to be blended with a conventional fuel before being able to be used in an airplane. This blending with a ratio of FT Light below $50 \%$ would lead to a distillation behavior even closer to that of the conventional fuel which was used for blending. 
In Figure 9, the aromatics content and the density of FT Light are shown in comparison to the CRC fuels. The CRC fuels are represented by grey dots each, as well as with the boxplot showing the statistical distribution. It is clearly visible that both properties of FT Light (blue stars) are limiting factors, since they are outside of the allowed range in ASTM D1655 and ASTM D7566, which is marked in green in Figure 9. The yellow range indicates an aromatic content, which is allowed by ASTM D1655, but not ASTM D7566. Red color indicates values outside of both ASTM D1655 and D7566.
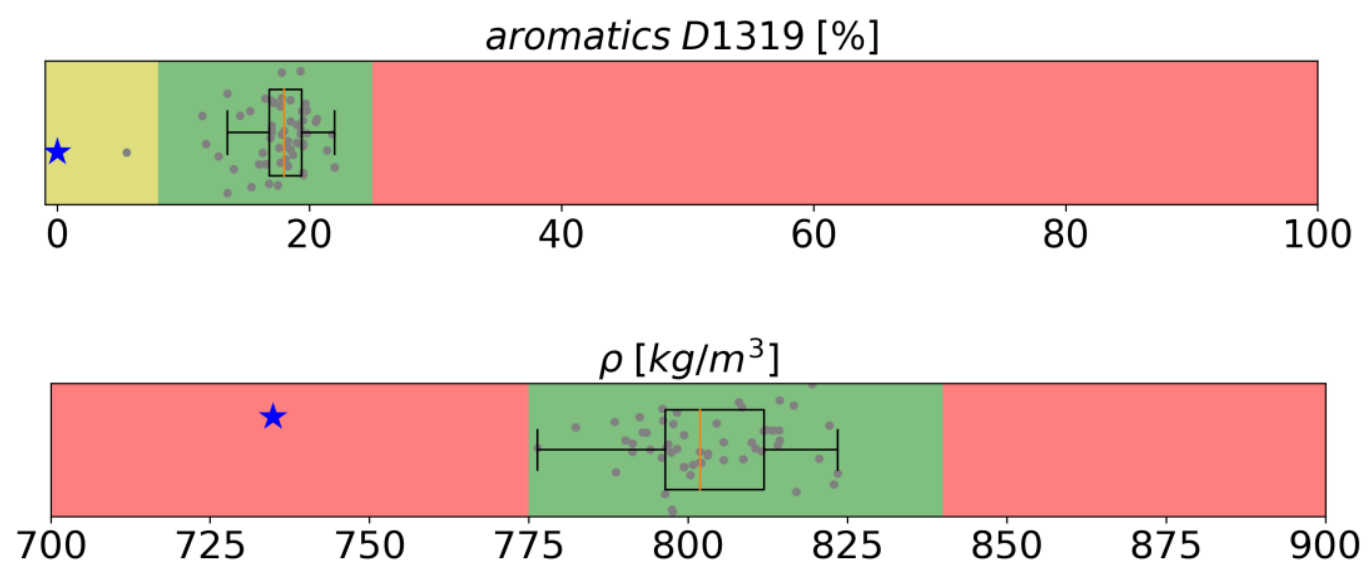

Figure 9: Aromatics content (upper) and density (lower) of FT Light (blue stars) in comparison to CRC fuels (grey dots). Statistical representation of the results by boxplots; open circles represent statistical outliers, green color indicates values within range of experience, yellow indicates the outlier region and red indicates values out of experience.

The maximum blending ratio is determined here with respect to the CRC fuels as blendstock. Linear mixing rules can be applied for both density and aromatic content. The maximum blending ratio for a synthetic blending component with property $\mathrm{v}_{\mathrm{syn}}$ in a blend with $\mathrm{a}$ conventional fuel with property $\mathrm{v}_{\text {conv }}$ is

$$
\mathrm{r}_{\text {syn,max }}=\frac{\mathrm{v}_{\text {lim,min }}-\mathrm{v}_{\text {conv }}}{\mathrm{v}_{\text {syn }}-\mathrm{v}_{\text {conv }}}
$$

The property $\mathrm{v}$ of the final blend is set to be equal to the lower limit $\mathrm{v}_{\text {lim,min }}$ of the specification range to achieve the maximum blending rate. For density, the lower limit is $775 \mathrm{~kg} / \mathrm{m}^{3}$. For aromatics, the lower limit is 8 vol\%. 


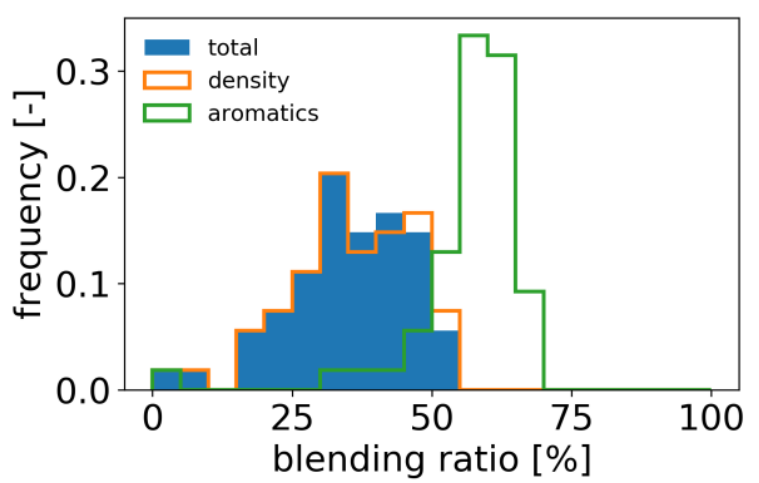

Figure 10: Histogram of the achievable maximum blending ratio of FT Light with respect to CRC fuels.

The histogram of the maximum blending ratio of FT Light with the CRC fuels as blendstock is shown in Figure 10. The green curve represents the histogram if only aromatic content would be taken into account for blending, while the orange curve represents the maximum blending ratio for density only. Both constraints have to be fulfilled, resulting in the blue area for the overall blending ratio. For most CRC fuels, density is the more critical property for blending. For aromatics only, the maximum blending ratio would be 67.2 vol\%. For the density only, the maximum would be 52.9 vol\%. The maximum for the final blending ratio considering both, density and aromatics, would be 52.4 vol\%.

Finally, it has to be considered that the higher the blending ratio, the lower the number of suitable fuels for blending. Hence only with a low blending ratio almost all conventional fuels could be used for blending. However, since the FT plant presented here is at a container scale and the production rate is low compared to large scale refineries, even a low blending ratio still could mean $100 \%$ turnover for the produced synthetic fuel.

\section{Conclusion}

The fuels already approved under the FT-SPK process, as stated in Annex A1 of ASTM D7566: "Fischer-Tropsch Hydroprocessed Synthesized Paraffinic Kerosine" utilizes hydrotreatment and is applied in large-scale plants. The herein presented plant features a unique and compact container-scale set-up, with no further downstream hydrotreatment. Main objective of this paper was to present and apply the methodology that was used to provide the fuel producer with fast feedback to find the minimum complexity of fuel processing technology to achieve a synthetic blending component for aviation fuels. As a first step in this iterative process the work presented here is focusing on assessing combustion relevant properties of the FT products. The focus and the aim of the presented work is to investigate 
the usability of FT Light as a blending component for conventional jet fuels. Further investigations concerning thermal and storage stability, as well as water content and freezing point are necessary, since these properties are likely to be critical for this fuel. However, exploring all relevant fuel properties as it will be mandatory within the ASTM approval process is beyond the scope of the present work. Future studies will focus on assessing and eventually improving properties regarding fuel stability and handling. Therefore reducing the alkene and alcohol content will be the main focus of further technical development of the FT process.

The most basic product of such a FT plant is the FT crude (see supporting information for detailed synthetic procedure steps). Due to its higher amount of longer chained hydrocarbons and its resulting higher final boiling point of over $350{ }^{\circ} \mathrm{C}$, FT crude cannot be used as blending component. In this work the focus is on assessing the combustion related properties of the produced FT Light.

From a combustion perspective, the produced FT Light is a promising candidate. It shows short ignition delay times and a high heating value. Also, the sooting tendency is lower, compared to conventional Jet A-1. For the neat FT Light three limiting factors prohibiting that it can be used as a fully synthetic aviation fuel have been identified: density, aromatics content and distillation.

To understand the effect of the out-of-specification distillation properties on combustion, the evaporation rate of the FT Light has been computed by high-fidelity model and compared to the evaporation rate of the CRC world fuel survey fuels. Results show that the FT Light is always within the range of evaporation rates of the conventional CRC fuels for all four operational conditions considered here: cold start, LBO, idle, and cruise. This indicates that the distillation is not the most critical property regarding the combustion behavior.

Regarding the two other limiting factors, density and aromatic content, blending with conventional Jet A-1 can be used so that the blend fulfills the ASTM D7566 requirements for the final blend, which are equal to the requirements for conventional fuel (ASTM D1655) plus some additional specifications, e.g. the minimum aromatics content. Blending FT Light with the CRC world fuel survey fuels results in a range of blending ratios from 0 to 52.4 vol\%. The blending ratio indicates the economic potential of FT Light. The highest blending ratios result in the highest direct turnover. However, the number of suitable conventional fuels for the highest blending ratios is very limited. For the herein presented container scale setup, which is producing small amounts of fuel, also low blending ratios are attractive since this still could mean $100 \%$ turnover. 
While the produced FT Light is a promising candidate from the combustion perspective and the limiting factors can be solved by blending with conventional fuels, future studies have to address properties regarding the fuel handling and storage. For example the high alkene content appears not significant for combustion; however its relevance for storage and thermal stability needs to be taken into consideration. The alcohol content also is not problematic for combustion, but due to its hydrophilic nature, icing issues can arise. These issues require further investigation concerning freezing point and water content measurements and likely improvements in the production process and application of respective additives before entering the certification process.

\subsection{Acknowledgements}

The authors gratefully acknowledge funding by the German Federal Ministry of Education and Research (BMBF) within the Kopernikus Project P2X, Cluster B2. The results related to $n$ alkanes are part of the Helmholtz Energy Alliance SynKWS. S.J., P.O. and M.K. thank Tobias Grein for GCMS and analytical support. Ineratec and IMVT acknowledge furthermore that parts of this work have been financially funded by the German Federal Ministry of Economy and Energy and the ESF - European Social Fund-Germany within the EXIST Business Start-Up Grant ("EXIST Forschungstransfer", grant agreement number 03EUGBW118). 


\section{Literature}

1. Moore, R. H.; Thornhill, K. L.; Weinzierl, B.; Sauer, D.; D'Ascoli, E.; Kim, J.; Lichtenstern, M.; Scheibe, M.; Beaton, B.; Beyersdorf, A. J.; Barrick, J.; Bulzan, D.; Corr, C. A.; Crosbie, E.; Jurkat, T.; Martin, R.; Riddick, D.; Shook, M.; Slover, G.; Voigt, C.; White, R.; Winstead, E.; Yasky, R.; Ziemba, L. D.; Brown, A.; Schlager, H.; Anderson, B. E., Biofuel blending reduces particle emissions from aircraft engines at cruise conditions. Nature 2017, 543, 411.

2. Lobo, P.; Christie, S.; Khandelwal, B.; Blakey, S. G.; Raper, D. W., Evaluation of Non-volatile Particulate Matter Emission Characteristics of an Aircraft Auxiliary Power Unit with Varying Alternative Jet Fuel Blend Ratios. Energy \& Fuels 2015, 29 (11), 7705-7711.

3. Schripp, T.; Anderson, B.; Crosbie, E. C.; Moore, R. H.; Herrmann, F.; Oßwald, P.; Wahl, C.; Kapernaum, M.; Köhler, M.; Le Clercq, P.; Rauch, B.; Eichler, P.; Mikoviny, T.; Wisthaler, A., Impact of Alternative Jet Fuels on Engine Exhaust Composition During the 2015 ECLIF Ground-Based Measurements Campaign. Environmental Science \& Technology 2018, 52 (8), 4969-4978.

4. IATA, Resolution on the commercial deployment on sutainable alternative fuel for aviation. In 73rd IATA annual general meeting, Cancun, Mexico, 2017.

5. Association, I. A. T., IATA Sustainable Aviation Fuel Roadmap. Montreal-Geneva, 2015.

6. Van Der Laan, G. P.; Beenackers, A. A. C. M., Kinetics and Selectivity of the Fischer-Tropsch Synthesis: A Literature Review. Catalysis Reviews 1999, 41 (3-4), 255-318.

7. Kook, S.; Pickett, L. M., Soot volume fraction and morphology of conventional, fischertropsch, coal-derived, and surrogate fuel at diesel conditions. SAE International Journal of Fuels and Lubricants 2012, 5 (2), 647-664.

8. Piermartini, P.; Boeltken, T.; Selinsek, M.; Pfeifer, P., Influence of channel geometry on Fischer-Tropsch synthesis in microstructured reactors. Chemical Engineering Journal 2017, 313, 328335.

9. Moses, C. A.; Roets, P. N. J., Properties, Characteristics, and Combustion Performance of Sasol Fully Synthetic Jet Fuel. ASME Turbo Expo 2008: Power for Land, Sea, and Air 2008, (43130), 431-443.

10. Hemighaus, G. B., T.; Bosley, C.; Organ, R.; Lind, J.; Brouette, R.; Thompson, T.; Lynch, J.; Jones, J., Alternative Jet Fuels: A supplement to Chevron's Aviation Fuels Technical Review. San Ramon, CA, 2006.

11. Moses, C. A.; Roets, P. N. J., Properties, Characteristics, and Combustion Performance of Sasol Fully Synthetic Jet Fuel. 2008, (43130), 431-443.

12. ASTM_D7566, Standard Specification for Aviation Turbine Fuel Containing Synthesized Hydrocarbons. ASTM International: PA, West Conshohocken, 2018; Vol. D 7566.

13. Chen, K.; Liu, H., The impacts of aromatic contents in aviation jet fuel on the volume swell of the aircraft fuel tank sealants. SAE International Journal of Aerospace 2013, 6 (2013-01-9001), 350354.

14. Baltrus, J.; Link, D.; Zandhuis, P.; Gormley, R. In Screening of potential o-ring swelling additives for ultra-clean transportation fuels, Abstracts of papers of the american chemical society, Amer chemical soc 1155 16TH ST, NW, Washington, DC 20036 USA: 2005; pp U1702-U1702.

15. Link, D. D.; Gormley, R. J.; Baltrus, J. P.; Anderson, R. R.; Zandhuis, P. H., Potential Additives to Promote Seal Swell in Synthetic Fuels and Their Effect on Thermal Stability. Energy \& Fuels 2008, 22 (2), 1115-1120. 
16. Baltrus, J. P.; Link, D. D.; Zandhuis, P. H.; Gormley, R. J.; Anderson, R. R., Screening of Potential O-Ring Swelling Additives for Ultraclean Transportation Fuels. In Ultraclean Transportation Fuels, American Chemical Society: 2007; Vol. 959, pp 197-208.

17. Moses, C. A.; Wilson, G.; Roets, P. N. J., Evaluation of Sasol Synthetic Kerosene For Suitability as Jet Fuel. In Part of the U.K. Aviation Fuels Committee Documentation, 2003.

18. Blakey, S.; Rye, L.; Wilson, C. W., Aviation gas turbine alternative fuels: A review. Proceedings of the Combustion Institute 2011, 33 (2), 2863-2885.

19. Lamprecht, D., Fischer-Tropsch Fuel for Use by the U.S. Military as Battlefield-Use Fuel of the Future. Energy \& Fuels 2007, 21 (3), 1448-1453.

20. Boeing's latest $777 \mathrm{~F}$ ecoDemonstrator flight programme tests $100 \%$ biofuel use and turbulence detection. GreenAir Communications 2018.

21. Jensen, B.; Longacre, J. 2018 ecoDemonstrator to begin flight testing. http://www.boeing.com/company/about-bca/washington/eco-demonstrator-03-02-18.page

(accessed 7.8. 2018).

22. Norris, G., Boeing begins 777 EcoDemonstrator tests: EcoDemonstrators have so far tested more than 80 technologies; the compact thrust reverser is fitted to the right-hand GE90-115B engine. Aviation Week \& Space Technology 2018.

23. Neuling, U.; Kaltschmitt, M., Techno-economic and environmental analysis of aviation biofuels. Fuel Processing Technology 2018, 171, 54-69.

24. Corporan, E.; DeWitt, M. J.; Belovich, V.; Pawlik, R.; Lynch, A. C.; Gord, J. R.; Meyer, T. R., Emissions Characteristics of a Turbine Engine and Research Combustor Burning a Fischer-Tropsch Jet Fuel. Energy \& Fuels 2007, 21 (5), 2615-2626.

25. DeWitt, M. J.; Corporan, E.; Graham, J.; Minus, D., Effects of Aromatic Type and Concentration in Fischer-Tropsch Fuel on Emissions Production and Material Compatibility. Energy \& Fuels 2008, 22 (4), 2411-2418.

26. Moore, R. H.; Shook, M.; Beyersdorf, A.; Corr, C.; Herndon, S.; Knighton, W. B.; Miake-Lye, R.; Thornhill, K. L.; Winstead, E. L.; Yu, Z.; Ziemba, L. D.; Anderson, B. E., Influence of Jet Fuel Composition on Aircraft Engine Emissions: A Synthesis of Aerosol Emissions Data from the NASA APEX, AAFEX, and ACCESS Missions. Energy \& Fuels 2015, 29 (4), 2591-2600.

27. Lobo, P.; Hagen, D. E.; Whitefield, P. D., Comparison of PM Emissions from a Commercial Jet Engine Burning Conventional, Biomass, and Fischer-Tropsch Fuels. Environmental Science \& Technology 2011, 45 (24), 10744-10749.

28. Corporan, E.; Edwards, T.; Shafer, L.; DeWitt, M. J.; Klingshirn, C.; Zabarnick, S.; West, Z.; Striebich, R.; Graham, J.; Klein, J., Chemical, Thermal Stability, Seal Swell, and Emissions Studies of Alternative Jet Fuels. Energy \& Fuels 2011, 25 (3), 955-966.

29. Schripp, T.; Köhler, M.; Wolters, F. airegEM Emissionseigenschaften von alternativen Luftfahrtkraftstoffen; 2017.

30. A. J. Beyersdorf, M. T. T., L. D. Ziemba, D. Bulzan, E. Corporan, S. C. Herndon, R. Howard, R. Miake-Lye, K. L. Thornhill,, E. Winstead,, C. Wey, Z. Yu, B. E. Anderson, Reductions in aircraft particulate emissions due to the use of Fischer-Tropsch fuels Atmos. Chem. Phys. 2014, 14, 11-23.

31. Moore, R. H.; Thornhill, K. L.; Weinzierl, B.; Sauer, D.; D’Ascoli, E.; Kim, J.; Lichtenstern, M.; Scheibe, M.; Beaton, B.; Beyersdorf, A. J.; Barrick, J.; Bulzan, D.; Corr, C. A.; Crosbie, E.; Jurkat, T.; Martin, R.; Riddick, D.; Shook, M.; Slover, G.; Voigt, C.; White, R.; Winstead, E.; Yasky, R.; Ziemba, L. D.; Brown, A.; Schlager, H.; Anderson, B. E., Biofuel blending reduces particle emissions from aircraft engines at cruise conditions. Nature 2017, 543 (7645), 411. 
32. Kärcher, B., The importance of contrail ice formation for mitigating the climate impact of aviation. J. Geophys. Res.-Atmos. 2016, 121 (7), 3497.

33. Moore, R. H.; Shook, M.; Beyersdorf, A.; Corr, C.; Herndon, S.; Knighton, W. B.; Miake-Lye, R.; Thornhill, K. L.; Winstead, E. L.; Yu, Z. H.; Ziemba, L. D.; Anderson, B. E., Influence of Jet Fuel Composition on Aircraft Engine Emissions: A Synthesis of Aerosol Emissions Data from the NASA APEX, AAFEX, and ACCESS Missions. Energy Fuels 2015, 29 (4), 2591.

34. Brem, B. T.; Durdina, L.; Siegeris, F.; Beyerle, P.; Bruderer, K.; Rindlisbacher, T.; Rocci-Denis, S.; Andac, M. G.; Zelina, J.; Penanhoat, O.; Wang, J., Effects of Fuel Aromatic Content on Nonvolatile Particulate Emissions of an In-Production Aircraft Gas Turbine. Environ. Sci. Technol. 2015, 49 (22), 13149.

35. Cain, J.; DeWitt, M. J.; Blunck, D.; Corporan, E.; Striebich, R.; Anneken, D.; Klingshirn, C.; Roquemore, W. M.; Vander Wal, R., Characterization of Gaseous and Particulate Emissions From a Turboshaft Engine Burning Conventional, Alternative, and Surrogate Fuels. Energy Fuels 2013, 27 (4), 2290.

36. Corporan, E.; Edwards, T.; Shafer, L.; DeWitt, M. J.; Klingshirn, C.; Zabarnick, S.; West, Z.; Striebich, R.; Graham, J.; Klein, J., Chemical, Thermal Stability, Seal Swell, and Emissions Studies of Alternative Jet Fuels. Energy Fuels 2011, 25 (3), 955.

37. Socolow, R.; Desmond, M.; Aines, R.; Blackstock, J.; Bolland, O.; Kaarsberg, T.; Lewis, N.; Mazzotti, M.; Pfeffer, A.; Sawyer, K. Direct air capture of $\mathrm{CO} 2$ with chemicals: a technology assessment for the APS Panel on Public Affairs; American Physical Society: 2011.

38. Caldeira, K.; Bala, G.; Cao, L., The Science of Geoengineering. Annual Review of Earth and Planetary Sciences 2013, 41 (1), 231-256.

39. Bundesministerium für Umwelt, N., Bau und Reaktorsicherheit, Klimaschutzplan 2050Klimapolitische Grundsätze und Ziele der Bundesregierung. 2016.

40. Umweltbundesamt, U., Berichterstattung unter der Klimarahmenkonvention der Vereinten Nationen und dem Kyoto-Protokoll 2018. Nationaler Inventarbericht zum Deutschen Treibhausgasinventar 1990-2016. . Dessau, 2018.

41. Xu, J.; Froment, G. F., Methane steam reforming, methanation and water-gas shift: I. Intrinsic kinetics. AlChE Journal 1989, 35 (1), 88-96.

42. Hadaller, O. J.; Johnson, J. M., World fuel sampling program. 2006.

43. Council, C. R., Handbook of aviation fuel properties. Society of Automotive Engineers, PA, USA

2004.

44. Yildirim, U.; Abanteriba, S., Manufacture, Qualification and Approval of New Aviation Turbine Fuels and Additives. Procedia Engineering 2012, 49, 310-315.

45. System, P. Q. I., DESC-BP, D. E. S. C., Ed. 8725 John Kingman Road, Ft. Belvoir, VA 22060-6222.

46. Rickard, G., The quality of aviation fuel available in the United Kingdom annual survey 2007. Report QinetiQ/08/01656, QinetiQ FLC, Cody Technology Park, Farnborough, UK GU14 OLX 2008.

47. IATA, IATA Guidance Material for Sustainable Aviation Fuel Management. 2015.

48. Moses, C. A., Comparative evaluation of semi-synthetic jet fuels. Contract 2008, 33415 (02D), 2299.

49. Nijs, H. H.; Jacobs, P. A., Metal particle size distributions and Fischer-Tropsch selectivity. An extended Schulz-Flory model. Journal of Catalysis 1980, 65 (2), 328-334.

50. Henrici-Olivé, G.; Olive, S., The Fischer-Tropsch synthesis: molecular weight distribution of primary products and reaction mechanism. Angewandte Chemie International Edition in English 1976, 15 (3), 136-141. 
51. Schulz, H.; Claeys, M., Kinetic modelling of Fischer-Tropsch product distributions. Applied Catalysis A: General 1999, 186 (1-2), 91-107.

52. Puskas, I.; Hurlbut, R. S., Comments about the causes of deviations from the AndersonSchulz-Flory distribution of the Fischer-Tropsch reaction products. Catalysis Today 2003, 84 (1), 99109.

53. Longwell, J. P., Synthetic fuels and combustion. Symposium (International) on Combustion 1977, 16 (1), 1-15.

54. ASTM, D., 4054-93 part B. Standard Practice for evaluating the compatibility of additives With Aviation-Turbine Fuels and Aircrafts fuel System Materials.

55. McDowellBomani, B. M.; Bulzan, D. L.; Centeno-Gomez, D. I.; Hendricks, R. C., Biofuels as an alternative energy source for aviation-a survey. 2009.

56. de Klerk, A., Chapter 10 - Aviation Turbine Fuels Through the Fischer-Tropsch Process. In Biofuels for Aviation, Chuck, C. J., Ed. Academic Press: 2016; pp 241-259.

57. Eddings, E. G.; Yan, S.; Ciro, W.; Sarofim, A. F., Formulation of a surrogate for the simulation of jet fuel pool fires. Combustion science and technology 2005, 177 (4), 715-739.

58. Riazi, M. R.; Daubert, T. E., Characterization parameters for petroleum fractions. Industrial \& engineering chemistry research 1987, 26 (4), 755-759.

59. Riazi, M. R.; Daubert, T. E., Prediction of molecular-type analysis of petroleum fractions and coal liquids. Ind. Eng. Chem. Process Des. Dev 1986, 25 (4), 1009-1015.

60. Oßwald, P.; Köhler, M., An atmospheric pressure high-temperature laminar flow reactor for investigation of combustion and related gas phase reaction systems. Rev. Sci. Instrum. 2015, 86 (10), 105.

61. Köhler, M.; Oßwald, P.; Xu, H.; Kathrotia, T.; Hasse, C.; Riedel, U., Speciation data for fuel-rich methane oxy-combustion and reforming under prototypical partial oxidation conditions. Chemical Engineering Science 2016, 139, 249-260.

62. Oßwald, P.; Köhler, M., An atmospheric pressure high-temperature laminar flow reactor for investigation of combustion and related gas phase reaction systems. Rev. Sci. Instrum. 2015, 86 (10), 105109.

63. Oßwald, P.; Whitside, R.; Schäffer, J.; Köhler, M., An experimental flow reactor study of the combustion kinetics of terpenoid jet fuel compounds: Farnesane, $p$-menthane and p-cymene. Fuel 2017, 187, 43.

64. Koehler, M.; Oßwald, P.; Krueger, D.; Whitside, R., Combustion Chemistry of Fuels: Quantitative Speciation Data Obtained from an Atmospheric High-temperature Flow Reactor with Coupled Molecular-beam Mass Spectrometer. JoVE (Journal of Visualized Experiments) 2018, (132), e56965-e56965.

65. Kathrotia, T.; Naumann, C.; Oßwald, P.; Köhler, M.; Riedel, U., Kinetics of Ethylene Glycol: The first validated reaction scheme and first measurements of ignition delay times and speciation data. Combustion and Flame 2017, 179, 172-184.

66. Oßwald, P.; Güldenberg, H.; Kohse-Höinghaus, K.; Yang, B.; Yuan, T.; Qi, F., Combustion of butanol isomers-a detailed molecular beam mass spectrometry investigation of their flame chemistry. Combustion and Flame 2011, 158 (1), 2-15.

67. Schenk, M.; Leon, L.; Moshammer, K.; Oßwald, P.; Zeuch, T.; Seidel, L.; Mauss, F.; KohseHöinghaus, K., Detailed mass spectrometric and modeling study of isomeric butene flames. Combustion and flame 2013, 160 (3), 487-503. 
68. Biordi, J. C., Molecular beam mass spectrometry for studying the fundamental chemistry of flames. Prog. Energy Combust. Sci. 1977, 3 (3), 151-173.

69. Battin-Leclerc, F., Detailed chemical kinetic models for the low-temperature combustion of hydrocarbons with application to gasoline and diesel fuel surrogates. Progress in Energy and Combustion Science 2008, 34 (4), 440-498.

70. Herrmann, F.; Oßwald, P.; Kohse-Höinghaus, K., Mass spectrometric investigation of the lowtemperature dimethyl ether oxidation in an atmospheric pressure laminar flow reactor. Proceedings of the Combustion Institute 2013, 34 (1), 771-778.

71. Wang, H.; Oehlschlaeger, M. A., Autoignition studies of conventional and Fischer-Tropsch jet fuels. Fuel 2012, 98, 249-258.

72. Gerrans, G.; Hartmann-Petersen, P.; Hartmann-Petersen, R., Sasol Encyclopaedia of Science and Technology. New Africa Books: 2004.

73. Violi, A.; Yan, S.; Eddings, E.; Sarofim, A.; Granata, S.; Faravelli, T.; Ranzi, E., Experimental formulation and kinetic model for JP-8 surrogate mixtures. Combustion Science and Technology 2002, 174 (11-12), 399-417.

74. Kallio, P.; Pásztor, A.; Akhtar, M. K.; Jones, P. R., Renewable jet fuel. Current Opinion in Biotechnology 2014, 26, 50-55.

75. Kim, D.; Martz, J.; Violi, A., A surrogate for emulating the physical and chemical properties of conventional jet fuel. Combustion and Flame 2014, 161 (6), 1489-1498.

76. Herbinet, O.; Pitz, W. J.; Westbrook, C. K., Detailed chemical kinetic mechanism for the oxidation of biodiesel fuels blend surrogate. Combustion and Flame 2010, 157 (5), 893-908.

77. Widegren, J. A.; Bruno, T. J., Thermal Decomposition Kinetics of the Aviation Turbine Fuel Jet A. Industrial \& Engineering Chemistry Research 2008, 47 (13), 4342-4348.

78. Hui, X.; Kumar, K.; Sung, C.-J.; Edwards, T.; Gardner, D., Experimental studies on the combustion characteristics of alternative jet fuels. Fuel 2012, 98, 176-182.

79. Schripp, T.; Herrmann, F.; Oßwald, P.; Köhler, M.; Zschoke, A.; Weigelt, D.; Mroch, M.; Werner-Spatz, C., Alternative Jet Fuels and Different Acceleration Behavior as Possible Aircraft Particle Emission Mitigation Strategies: Experiments at a Jet Engine Test Rig. submitted 2018.

80. Kaltschmitt, M.; Neuling, U., Biokeresoene: Status and prospects. Springer-Verlag: Berlin, 2018.

81. Heyne, J. S.; Colket, M. B.; Gupta, M.; Jardines, A.; Moder, J. P.; Edwards, J. T.; Roquemore, M.; Li, C.; Rumizen, M. In Year 2 of the National Jet Fuels Combustion Program: Towards a Streamlined Alternative Jet Fuels Certification Process, 55th AIAA Aerospace Sciences Meeting, 2017; p 0145.

82. Butze, H. F.; Smith, A. L., Effect of fuel properties on performance of single aircraft turbojet combustor at simulated idle, cruise, and takeoff conditions. 1977.

83. Eckel, G. Large eddy simulation of turbulent reacting multi-phase flows. Stuttgart, 2018.

84. Le Clercq, P.; Doué, N.; Rachner, M.; Aigner, M. In Validation of a multicomponent-fuel model for spray computations, 47th AIAA Aerospace Sciences Meeting including The New Horizons Forum and Aerospace Exposition, 2009; $p 1188$. 